\title{
Laser Surface Hardening of Ni-hard White Cast Iron
}

\author{
Samar Reda Al-Sayed ${ }^{1, *(\mathbb{C}}$, Ahmed Magdi Elshazli ${ }^{1}$ and Abdel Hamid Ahmed Hussein ${ }^{2}$ \\ 1 National Institute of Laser Enhanced Sciences (NILES), Cairo University, Giza 12611, Egypt; \\ eg.engshazly@yahoo.com \\ 2 Faculty of Engineering, Cairo University, Giza 12611, Egypt; aahussein41@yahoo.com \\ * Correspondence: sreda@niles.edu.eg; Tel.: +20-10-6654-8019
}

Received: 15 May 2020; Accepted: 5 June 2020; Published: 16 June 2020

\begin{abstract}
Laser surface treatment on two different types of nickel-chromium white cast iron (Ni-hard) alloys (Ni-hard 1 and Ni-hard 4) was investigated. Nd:YAG laser of 2.2-kw with continuous wave was used. Ni-hard alloys are promising engineering materials, which are extensively used in applications where good resistance to abrasion wear is essential. The conventional hardening of such alloys leads to high wear resistance nevertheless, the core of the alloy suffers from low toughness. Therefore, it would be beneficial to harden the surface via laser surface technology which keeps the core tough enough to resist high impact shocks. A laser power of different levels (600, 800 and 1000 Watts) corresponding to three different laser scanning speeds $\left(3,4\right.$ and $\left.5 \mathrm{~m} \cdot \mathrm{min}^{-1}\right)$ was adopted hoping to reach optimum conditions for wear resistance and impact toughness. The optimum condition for both properties was recorded at heat input of $16.78 \mathrm{~J} \cdot \mathrm{mm}^{-2}$. The present findings reflect that the microhardness values and wear resistance clearly increased after laser hardening by almost three times due to laser surface hardening, whereas, the impact toughness was increased from five joules obtained from conventionally heat-treated samples to $6.4 \mathrm{~J}$ as gained from laser-treated samples.
\end{abstract}

Keywords: laser surface treatment; nickel-chromium white cast iron; microhardness; hardened depth; wear resistance; impact toughness

\section{Introduction}

Ni-hard is the common name for a family of white cast irons alloyed with nickel and chromium which are known of their high hardness and outstanding resistance to abrasion wear. These alloys are extensively used in mining and mineral processing industries, such as hammers, crushers, ball mills and pulverizing rolls [1,2]. There are two different groups of Ni-hard composition: (i) the medium alloyed Ni-hard 1 and Ni-hard 2 with nominally $2.6 \mathrm{wt} \% \mathrm{C}, 4 \mathrm{wt} \% \mathrm{Ni}, 2 \mathrm{wt} \% \mathrm{Cr}$ and (ii) Ni-Hard 4 with, nominally $3 \mathrm{wt} \% \mathrm{C}, 8-10 \mathrm{wt} \% \mathrm{Cr}, 4-6 \mathrm{wt} \% \mathrm{Ni}, 2 \mathrm{wt} \% \mathrm{Si}$ [3].

Ni-hard 1 alloys contain about $44 \% \mathrm{M}_{3} \mathrm{C}$ type carbide embedded in an iron matrix [4]. Their solidification begins with formation of proeutectic austenite followed by eutectic reaction (liquid solidify into austenite $+\mathrm{M}_{3} \mathrm{C}$ [5]. Upon cooling to room temperature, austenite transforms to martensite [6,7]. Ni-hard 4 is designed to give a microstructure of eutectic $M_{7} C_{3}$ carbides embedded in a metallic matrix that is predominantly austenite in the as-cast condition, but, after hardening heat treatments, the matrix is predominantly martensitic [8]. Carbon content of Ni-hard 4 is kept between 2.8 and $3.2 \mathrm{wt} \%$ as a compromise between abrasion resistance and fracture toughness. Carbon content determines the volume fraction of eutectic carbides since most of it enters the carbide phase together with iron, chromium and other carbide-forming elements present [9]. A minimum content of about $5 \mathrm{wt} \% \mathrm{Ni}$ should be maintained to inhibit pearlite formation during slow cooling of the casting. Silicon addition above $1.5 \mathrm{wt} \%$ hinders the peritectic reaction and thus favors the formation of entirely eutectic $\mathrm{M}_{7} \mathrm{C}_{3}$ carbides. Lower silicon contents lead to formation of mixed carbide morphologies of $\mathrm{M}_{3} \mathrm{C}$ and $\mathrm{M}_{7} \mathrm{C}_{3}$, which may impair both abrasion resistance and fracture toughness [10]. 
Chromium is included in these alloys to counteract the graphitizing effect of nickel and thus ensures that the irons will solidify white according to the metastable eutectic reactions. The composition selected for the Ni-Cr white iron alloy depends on the properties required for the service conditions, as well as on the dimensions and weight of the casting [11]. The alloying elements included tend to improve the wear resistance of nickel-chromium white irons by forming harder carbides; and moreover, they may partition to the matrix and thus improve the hardenability of the matrix [12]. Unfortunately, nickel-chromium white cast iron is still a kind of brittle material. It cannot meet the demand of severe working conditions, such as high impact wear conditions. Therefore, the aims of higher abrasion resistance and better toughness at an acceptable cost have been the guidelines for development of this useful material. Consequently, every attempt to improve the impact toughness together with superior wear resistance, tends to widen the application of white cast irons [8].

The surface treatments are usually applied to enhance the material surface properties such as hardness, as well as wear and corrosion resistance in order to meet the high performance and reliability of industrial requirements [13,14]. In this context, laser hardening is a promising process for the ferrous family to produce a hardened layer on the surface. During the process, a laser scans across the material, acting as a source, to heat a thin surface layer of a massive material to reach the austenitization temperature $[15,16]$. This process avoids most of the restrictions observed in the conventional surface treatment such as energy and time consumption, complex heat treatment schedule, non-controllable heat affected zones, and the necessity of a quenchant [17].

In view of such advantages, many studies are concerned with laser surface hardening, e.g., Hwang et al, [18] investigated the effect of laser power and travel speed on the characteristics of the laser-hardened layer of gray cast iron. They found that the hardness of the laser-hardened layer was in a range between 800 and $950 \mathrm{Hv} 0.1$, regardless of the laser power and the wear resistance was doubled. Duffet et al, [19] examined the use of Nd:YAG laser in the treatment of cast iron cylinder bore of automobile engines, the laser beams allowed holes on the initial bore texture to be obtained and significantly yields larger hydrodynamic regime. Furthermore, Slatter et al, [20] applied a $\mathrm{CO}_{2}$ laser to treat the valve seat area of a cast iron cylinder head and the results from the impact testing showed a very hard surface that decreased wear. Regarding the work of M. Adel et al, [21] the use of $\mathrm{Nd}-$ YAG pulsed wave laser modified and refined the surface microstructure of acicular bainitic ductile iron, also the wear rate increased with the increasing in the normal loads at constant sliding speed and sliding time. Majlinger et al, [22] studied the laser-treated layer of cast iron cylinder bores with lamellar graphite, the near surface area of the cylinder bore becomes harder and more wear resistant, furthermore, due to the inhomogeneity of the pearlitic matrix and graphite lamellae, oil reserving holes are formed. Both G. Marest et al, [23] and D. Pantelis et al. [24] used excimer laser to heat treat different types of cast iron alloys, the microstructure and hardness were improved after laser hardening.

This study was thus planned to enhance the wear resistance of the Ni-hard alloys as well as the impact toughness via a proper selection of laser surface-hardening method, particularly in light of the rather scarce studies on such alloys reported in this respect. Indicative values resulting from previous experimentations and from the industrial state of the art show that the minimum depth of the treated area should be around $0.25 \mathrm{~mm}$ with a valid reference value for the superficial microhardness value of $\sim 700$ HV [14].

\section{Material and Methods}

The aim of this study is to achieve a good hardened layer of Ni-hard 1 and 4 alloys by means of laser hardening process, and it was necessary to know the quality and microstructure of the laser hardened zone. The possible strategy was to investigate the hardened layers microstructure by using optical and scanning electronic microscopy, energy dispersive X-ray (EDX) microanalyzer, X-ray diffraction (XRD), microhardness and wear tests. These tools could help to analyze whether the layer after laser-hardening was suitable for practical use. Through the analysis of the microstructure of the 
hardened layer, it was possible to know the distributions of the compositions, cracks and porosities, such information and experiment data were very useful for the further process improvement.

\subsection{Overall, Work Strategy}

(1) Casting and preparation of two different types of Ni-hard (Ni-hard 1 \& Ni-hard 4) alloys;

(2) Achievement of laser surface hardening on such types of Ni-hard alloys and then, for comparison purpose conventional heat treatment was performed as well;

(3) Surface morphology and microstructure investigation by using optical and scanning electronic microscopy followed by X-Ray diffraction (XRD) was performed;

(4) Tribological tests (Microhardness and abrasive wear tests) were accomplished.

(5) Finally, room temperature impact toughness test was carried out.

\subsubsection{Specimen Preparation (Melting and Casting)}

Two nickel-chromium white cast iron (Ni-hard) alloys were cast in a rod form with the dimensions of $15 \mathrm{~mm} \times 15 \mathrm{~mm} \times 80 \mathrm{~mm}$ and the chemical composition listed in Table 1. Samples measuring $10 \mathrm{~mm} \times 10 \mathrm{~mm} \times 55 \mathrm{~mm}$ were machined for laser surface treatment. Prior to the laser hardening, the surface of the Ni-hard samples was cleaned with acetone [25].

Table 1. Chemical composition of the Ni-hard alloys used.

\begin{tabular}{cccccc}
\hline \multirow{2}{*}{ Sample Number } & \multicolumn{5}{c}{ Chemical Composition (\%) } \\
\cline { 2 - 6 } & $\mathbf{C}$ & $\mathbf{S i}$ & $\mathbf{M n}$ & $\mathbf{N i}$ & $\mathbf{C r}$ \\
\hline $\begin{array}{c}\text { Sample 1 (S1) } \\
\text { Ni-hard 1 }\end{array}$ & 3.10 & 0.70 & 0.77 & 4.00 & 2.44 \\
\hline $\begin{array}{c}\text { Sample 2 (S2) } \\
\text { Ni-hard 4 }\end{array}$ & 2.77 & 2.00 & 0.50 & 5.50 & 9.40 \\
\hline
\end{tabular}

\subsubsection{Laser Surface Hardening Process}

A $2.2 \mathrm{~kW}$ Rofin-Sinar continuous wave diode pumped Nd:YAG laser $(\lambda=1064 \mathrm{~nm})$ was used to generate the laser beam. The laser beam was delivered to the rotating head by means of a fiber optic, the laser radiation focused on the sample surface by means of a focusing lens of focal length $f=120 \mathrm{~mm}$, producing a beam spot size of $1.2 \mathrm{~mm}$ on the substrate. The oscillation mode is a multimode with Gaussian energy distribution. The laser treatment was carried out in argon shielding gas with a flux of $10 \mathrm{~L} \cdot \mathrm{min}^{-1}$ to minimize the oxidation of the hardened surface. Preliminary experiments with different laser power values were executed through the previous studies [18-21]. Eventually, a range of laser treatment parameters was chosen to determine the optimum processing conditions for surface treatment. In the present investigation, three different laser powers were attempted with three different laser scanning speeds (as listed in Table 2). The samples are abbreviated as S1-P-V and S2-P-V, where P stands for laser power and $\mathrm{V}$ for scanning speed. Laser hardening was achieved by parallel tracks with $25 \%$ overlap; this overlap ratio was chosen to avoid any overheating and any discontinuation in the profile. [25].

Heat input values were calculated to combine the effect of laser power with the scanning speed and the laser beam diameter into one value. Heat input was calculated according to the following equation $\mathrm{H}=\mathrm{P} / \mathrm{D} \cdot \mathrm{V}$ where: $\mathrm{H}$ : heat input $\left(\mathrm{J} \cdot \mathrm{mm}^{-2}\right)$, $\mathrm{P}$ : laser power $\left(\mathrm{J} \cdot \mathrm{s}^{-1}\right)$, D: beam diameter $(\mathrm{mm})$ and $\mathrm{V}$ : laser scanning speed $\left(\mathrm{mm} \cdot \mathrm{s}^{-1}\right)$ [26].

To achieve comparison purpose, a conventional heat treatment (CHT) was subjected to the samples; samples were austenitized at $800{ }^{\circ} \mathrm{C}$ for $8 \mathrm{~h}$, and subsequently cooled inside the furnace with slow cooling rate of $30^{\circ} \mathrm{C} / \mathrm{h}$. To improve the impact toughness, subcritical treatments (tempering) were carried out on the CHT samples. The samples were held to $300^{\circ} \mathrm{C}$ for four hours followed by air cooling, see Figure 1. 
Table 2. The laser surface treatment parameters.

\begin{tabular}{|c|c|c|c|}
\hline Sample No. S-P-V & Laser Power P (kW) & Laser Scanning Speed $\mathrm{v}\left(\mathrm{m} \cdot \mathrm{min}^{-1}\right)$ & Heat Input $\left(\mathrm{J} \cdot \mathrm{mm}^{-2}\right)$ \\
\hline S1/S2-1-3 & 1.0 & 3 & 16.78 \\
\hline $\mathrm{S} 1 / \mathrm{S} 2-1-4$ & 1.0 & 4 & 12.50 \\
\hline S1/S2-1-5 & 1.0 & 5 & 10.00 \\
\hline S1/S2-0.8-3 & 0.8 & 3 & 13.33 \\
\hline S1/S2-0.8-4 & 0.8 & 4 & 10.00 \\
\hline S1/S2-0.8-5 & 0.8 & 5 & 8.00 \\
\hline S1/S2-0.6-3 & 0.6 & 3 & 10.00 \\
\hline S1/S2-06-4 & 0.6 & 4 & 7.50 \\
\hline S1/S2-0.6-5 & 0.6 & 5 & 6.00 \\
\hline
\end{tabular}

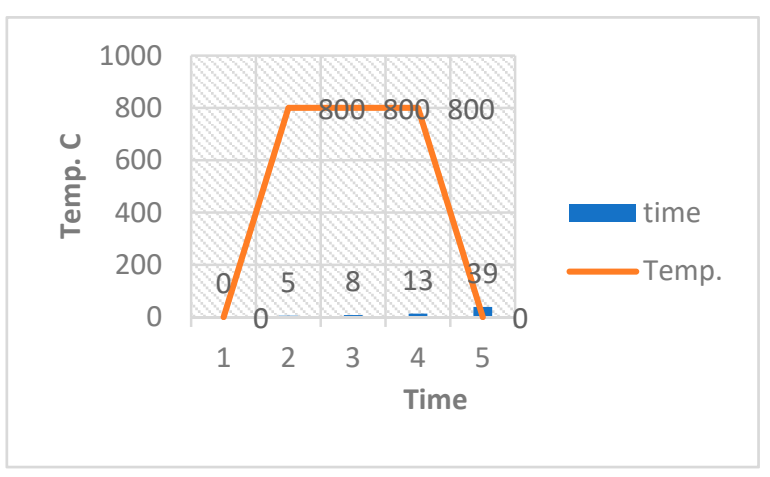

(a)

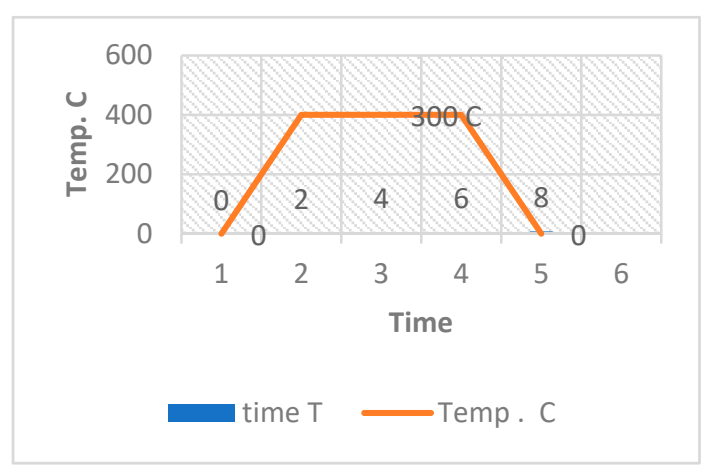

(b)

Figure 1. Conventional heat treatment process; (a) hardening heating and cooling cycles and (b) tempering heating and cooling cycles.

\subsubsection{Microstructural Analysis}

Metallographic samples were prepared using standard procedures of mechanical polishing and then were etched with Vilella's reagent $(5 \mathrm{~mL} \mathrm{HCl}, 1 \mathrm{~g}$ picric acid in $100 \mathrm{~mL}$ ethanol) or nital ( $6 \% \mathrm{HN} 03$ in methyl alcohol) for $10 \mathrm{~s}$. The microstructures of the samples were examined using the Axiotech 30 optical microscope (Lukas Microscope Service, Inc., Hillview Court, Mundelein, IL, USA) and the hardened layer was examined by means of back-scattered electron mode of the QUANTA FEG 250 SEM (FEI, Hillsboro, OR, USA) equipped with an energy dispersive X-ray (EDX) microanalyzer. Additionally, the phases present in the surface layer were determined by X-ray diffraction (XRD) with a diffractometer model (XPert Pro Analytical $45 \mathrm{~V}, 40 \mathrm{~mA}$ with source copper $\lambda=1.54 \AA$ Poland) using $\mathrm{CuK} \alpha$ radiation in a $2 \theta$ range of $30-120^{\circ}$ and to record data at 0.02 degrees steps at a speed of 0.004 degrees/min.

\subsubsection{Mechanical and Tribological Tests}

Microhardness Test

Vickers surface hardness of the as-cast (AC), CHT and LHT samples were measured under a load of $10 \mathrm{~kg}$, the full load being normally applied for $15 \mathrm{~s}$, according to ASM G 132 [27]. Each measured hardness value was an average of five readings for each condition. Additionally, the distribution of Vickers microhardness along the hardened depth to the base metal (BM) was measured under a load of $500 \mathrm{~g}$ for $20 \mathrm{~s}$.

\section{Abrasive Wear Test}

Unlubricated pin-on-ring wear test for CHT and LHT samples was applied at room temperature. The wear test was performed on the samples after treatments, without any surface preparation for the samples. The pin-on-ring abrasive wear test involved high stress, two-body abrasion, in which one 
end of a rectangular pin specimen was fixed against rotating abrasive silicon carbide ring having a diameter of $250 \mathrm{~mm}$ and hardness of $2600 \mathrm{HV} 0.05$. The experimental conditions used for the wear test were; normal loads $=60-\mathrm{N}$ and fixed rotation speed of $785 \mathrm{rpm}$ for $20 \mathrm{~min}$. The weight loss was measured by a weighing method, and each specimen was weighed before and after wear testing by using a sensitive digital balance of accuracy $10^{-4} \mathrm{~g}$. The wear extent was measured by weight loss taking an average of at least three runs. The wear rate $\left(\mathrm{mg} \cdot \mathrm{min}^{-1}\right)$ was measured as well.

Impact Toughness

Furthermore, Room temperature impact toughness measurements were carried out using an impact tester, model JB-W500 (TIME Group, Inc., Beijing, China). The impact machine has maximum impact energy of $500 \mathrm{~J}$, maximum impact speed of $5.4 \mathrm{~m} \cdot \mathrm{s}^{-1}$, minimum impact energy resolution of $0.2 \mathrm{~J}$ and rising angle of $150^{\circ}$. The samples with nominal dimensions of $10 \mathrm{~mm} \times 10 \mathrm{~mm} \times 55 \mathrm{~mm}$, were used as un- notched samples according to ASTM A327standard [28]. The result is usually reported as the energy in $\mathrm{J}$ required to fracture the test piece. The impact toughness values are the averages of three tests.

\section{Results and Discussion}

\subsection{Microstructural Analysis}

\subsubsection{The As-Cast Microstructure}

The microstructure of the as cast S1 sample consists of primary austenite dendrites and the carbide eutectic; the eutectic $\left(\mathrm{M}_{3} \mathrm{C}\right)$ carbide morphology is continuous within the matrix (the dark acicular streaks are martensite and lighter areas are austenite) as shown in Figure 2a. Their solidification begins with formation of proeutectic austenite followed by a eutectic reaction of liquid to austenite + $\mathrm{M}_{3} \mathrm{C}$. Upon cooling to room temperature, austenite partially transforms to martensite [29]. While the microstructure of the as cast $\mathrm{S} 2$ sample contains rod like eutectic $(\mathrm{Cr}, \mathrm{Fe})_{7} \mathrm{C}_{3}$ carbide with a matrix of austenite (lighter areas) and acicular martensite (darker areas) as shown in Figure $2 \mathrm{~b}$. The formation of eutectic $(\mathrm{Cr}, \mathrm{Fe})_{7} \mathrm{C}_{3}$ instead of $\mathrm{M}_{3} \mathrm{C}$ carbides may be attributed to high contents of both silicon $(2 \mathrm{wt} \%)$ and nickel (5.5 wt\%) in the alloys [1]. Through solidification, silicon is excluded into the melt; this increases the carbon activity within the melt, and thus promoting the formation of $(\mathrm{Cr}, \mathrm{Fe})_{7} \mathrm{C}_{3}$ carbides during the eutectic reaction. The high content of nickel lowers the peritectic temperature, thereby giving additional time for the initial $(\mathrm{Cr}, \mathrm{Fe})_{7} \mathrm{C}_{3}$ carbides to proceed to completion [6]. Some secondary carbides (SC) were detected as identified by EDX and XRD techniques. All phases were chemically analyzed by EDX and are in accord with previous literatures [30].

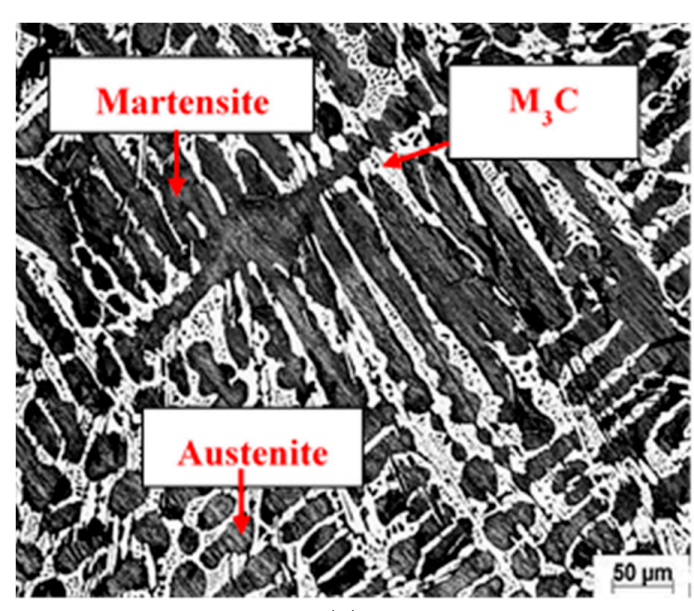

(a)

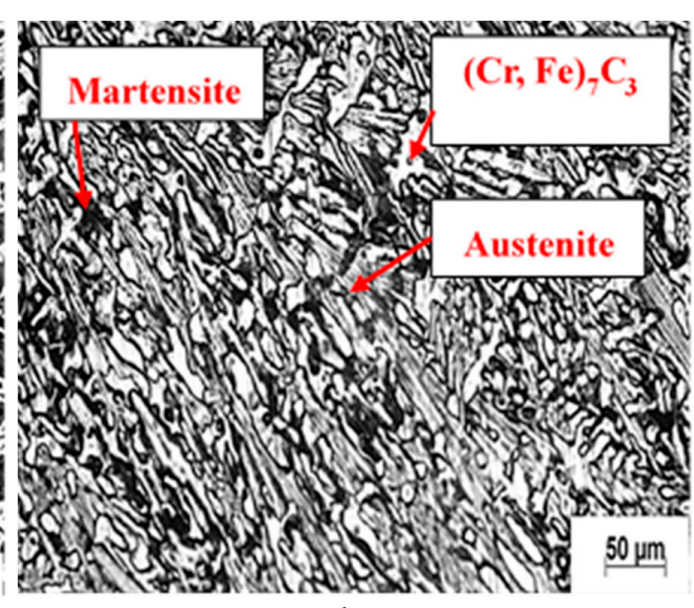

(b)

Figure 2. Optical microstructure of the as-cast (a) S1 (Ni-hard 1) sample (b) S2 (Ni-hard 4) sample. 


\subsubsection{Microstructure after Conventional Heat Treatment $(\mathrm{CHT})$}

After solidification of both (S1 and S2) samples, most of austenite transformed to martensite and some granular bainite. Therefore, the microstructures contain martensite, some bainite, retained austenite and more secondary carbides, as shown in Figure 3.

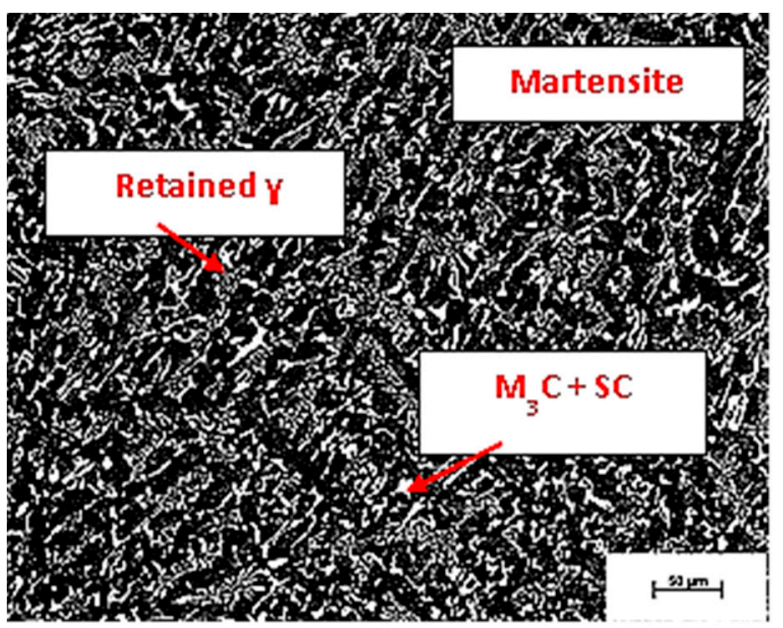

(a)

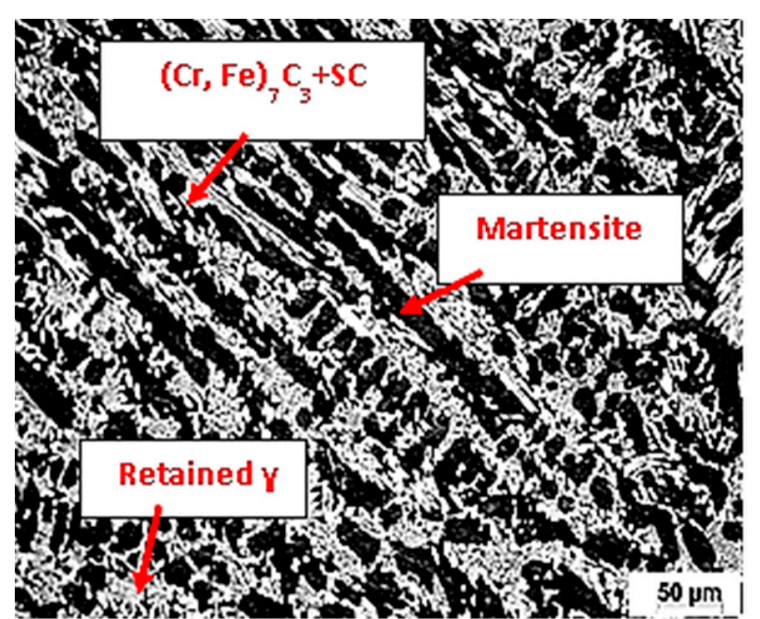

(b)

Figure 3. Optical microstructure of the conventional heat treatment (CHT) samples (a) S1 sample (b) S2 sample.

\subsubsection{Microstructure of S1 (Ni-hard 1) after Laser Heat Treatment (LHT)}

Low magnification optical image showing the entire tracks of laser treatment to provide obvious insight about the depth of modification is presented in Figure 4. Figure 5 shows typical optical micrographs of samples treated at a laser power of $1000 \mathrm{~W}$. The surface layer of all samples was free of cracks and pores. The microstructure after LHT shows a sequence of three regions based on their different microstructures: (i) the transformed hardened zone (HZ), (ii) the heat affected zone (HAZ) and (iii) the unaffected cast metal (CM), respectively. A similar microstructure was obtained in all specimens treated at various laser processing parameters.

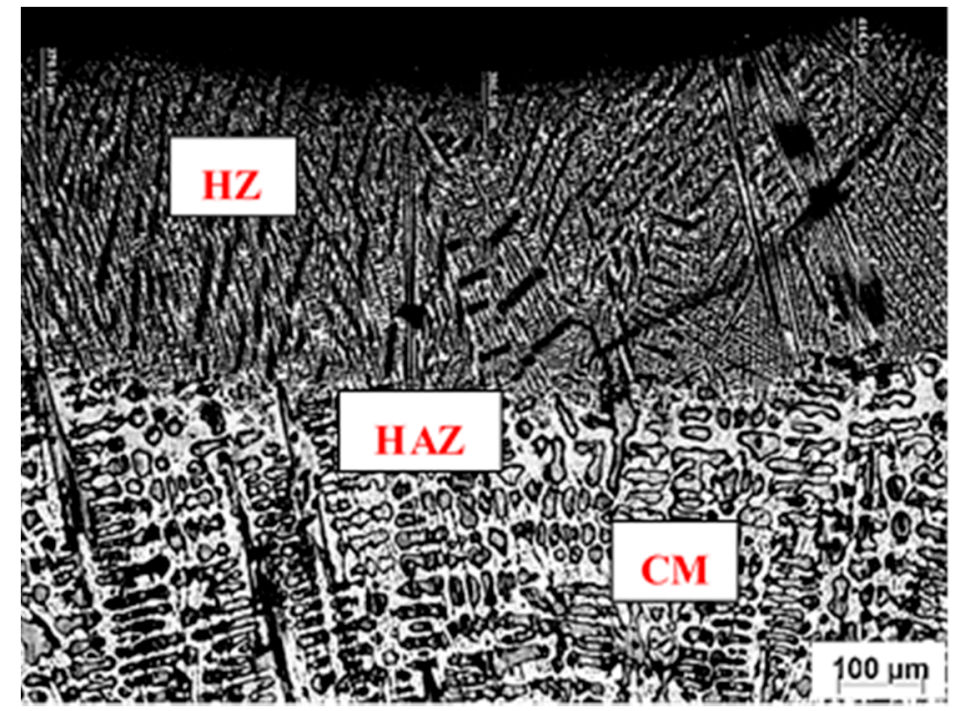

Figure 4. Optical image of the entire laser-treated area of LHT S1-1-4 sample; hardened zone (HZ), heat affected zone (HAZ) and cast metal (CM). 


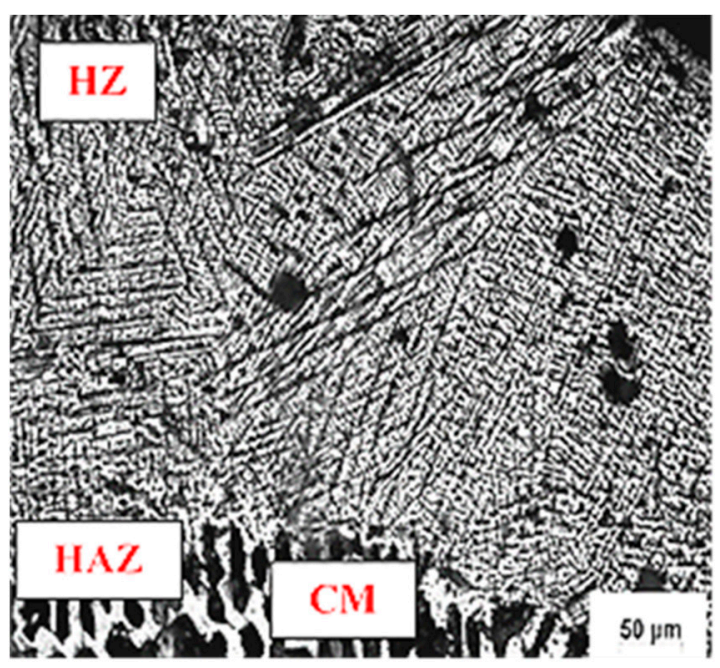

(a)

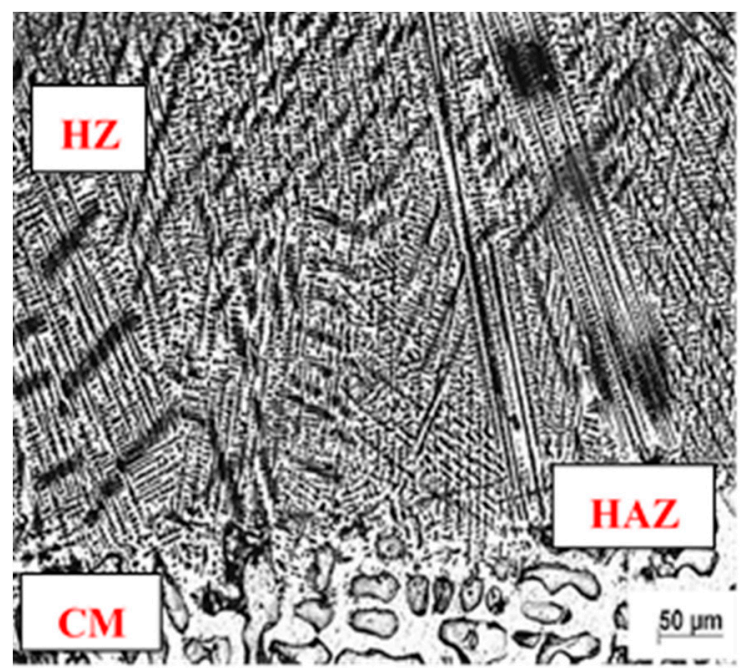

(b)

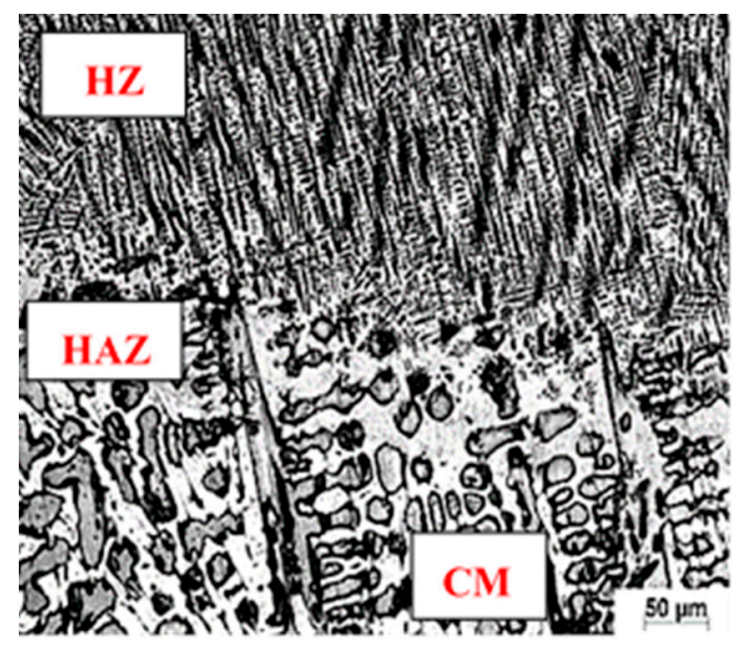

(c)

Figure 5. Typical microstructure features of laser heat-treated (LHT) S1 (Ni-hard 1) samples at a constant power of $1000 \mathrm{~W}$ and different laser scanning speeds: (a) 3; (b) 4 ; (c) and $5 \mathrm{~m} \cdot \mathrm{min}^{-1}$.

Additional information of both hardened zones and heat affected zones was obtained from the SEM micrographs of the laser surface-treated samples at a higher magnification, as presented in Figure 6. The transformed hardened zone (HZ) is the area where transformations occur in the solid state. During laser heating, the matrix transforms into a carbon-rich austenite, into which additional carbon diffuses from eutectic carbides. During rapid self-quenching, the carbon-rich austenite transforms into martensite with some retained austenite [31]. Consequently, the HZ contains ultrafine martensite, retained austenite and eutectic $\mathrm{M}_{3} \mathrm{C}$ carbides. While, an irregular carbide $\left(\mathrm{M}_{3} \mathrm{C}\right)$ plates dispersed within the dendritic matrix structure was observed in the HAZ due to the redistribution of a larger amount of un-dissolved carbides. Additional evidence of the laser surface hardening emerges from the XRD analysis as appears in Figure 7. The identified phases are in accordance with the obtained microstructure. 


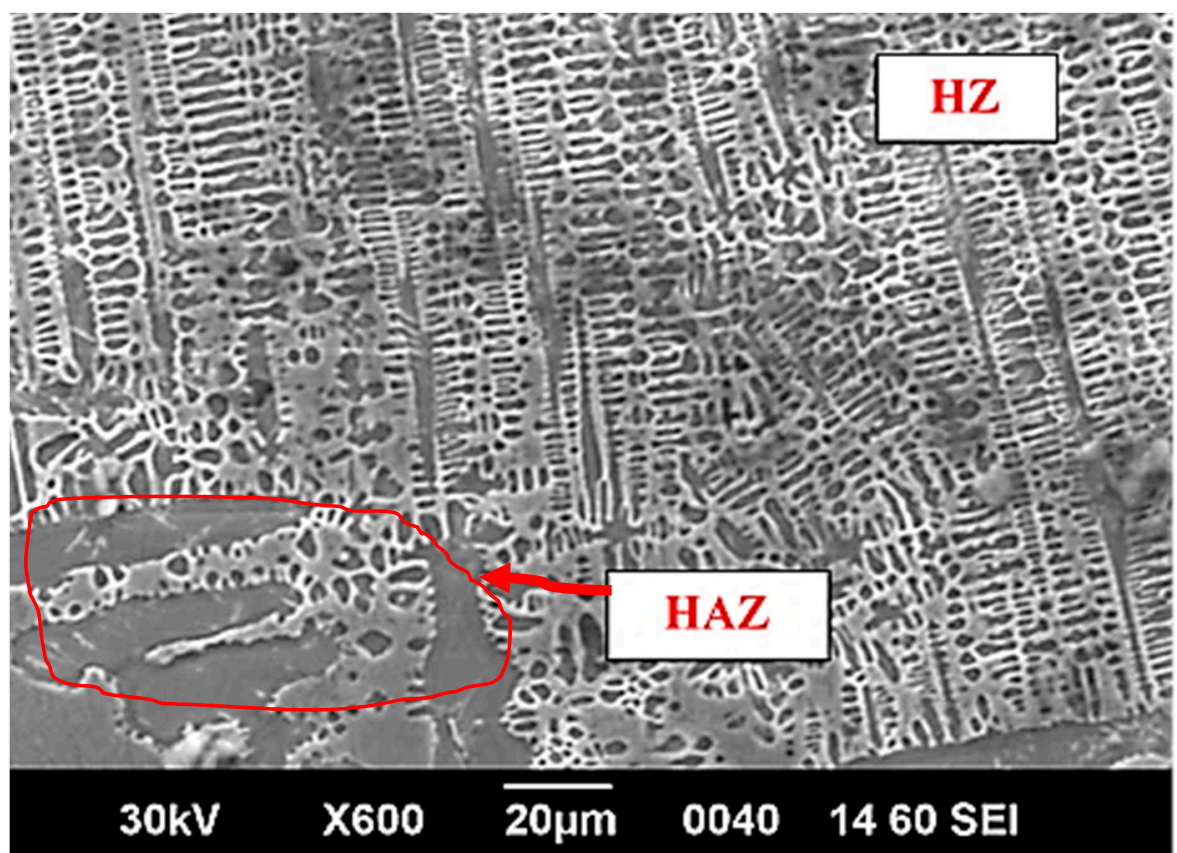

Figure 6. SEM microstructure: of the HZ and the HAZ of S1-1-3 sample.

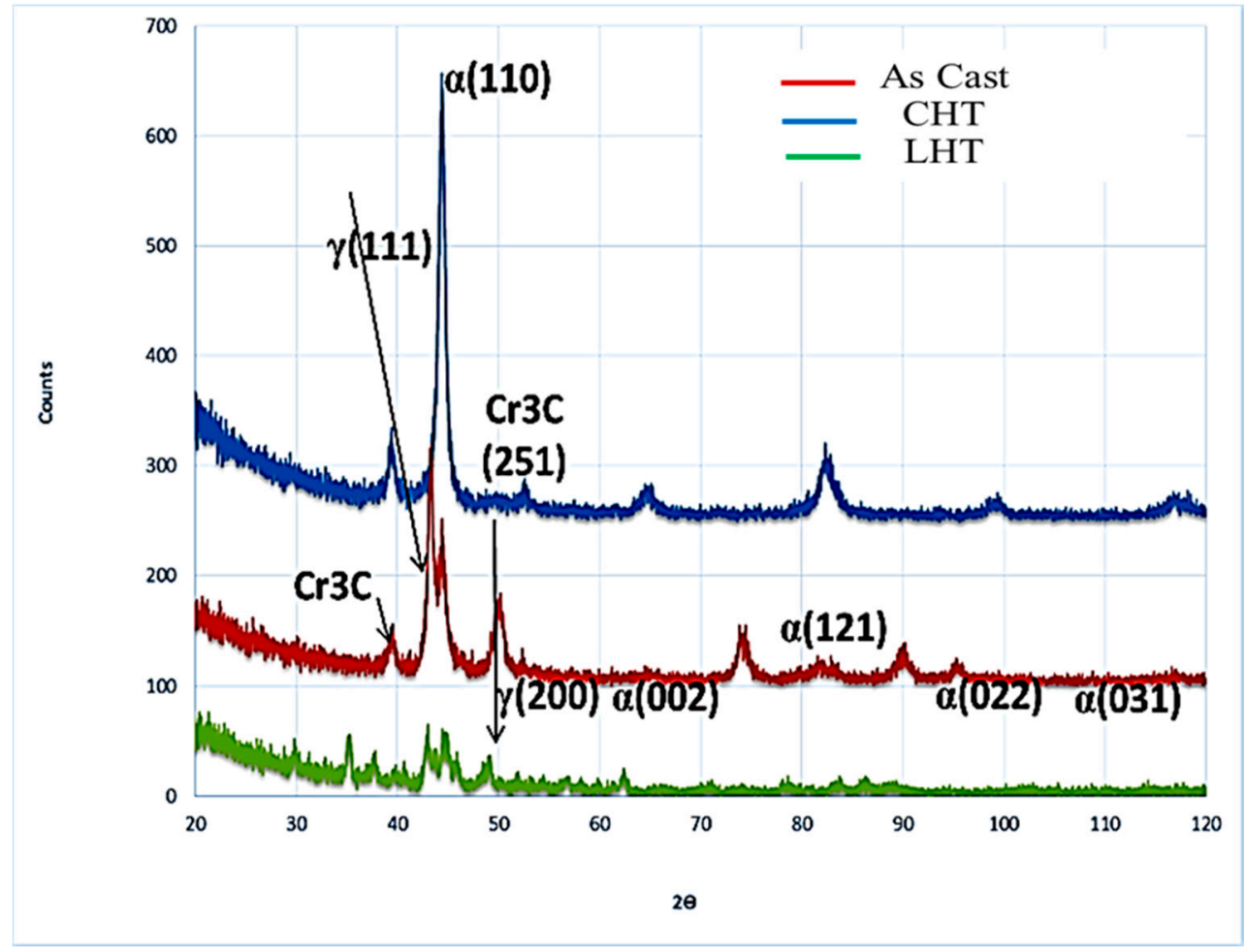

Figure 7. XRD Pattern of the S1 (Ni-hard 1) as-cast, conventionally heat-treated and laser-treated samples.

\subsubsection{Microstructure of S2 (Ni-hard 4) after Laser Heat Treatment (LHT)}

Figure 8 also reveals similar austenite transformation to fine martensite plates which has occurred in the HZ. Due to high carbon content $(2.77 \%)$ in S2 sample, the martensite starting temperature (MS) drops below room temperature and thus the austenite is retained. As a result of its high alloy content, as-cast Ni-hard 4 usually contains over $50 \%$ retained austenite and more complete austenite 
transformation to martensite is achieved by destabilization of the austenite at temperature above $750{ }^{\circ} \mathrm{C}$, where austenite stability is lowered by carbide precipitation [30].

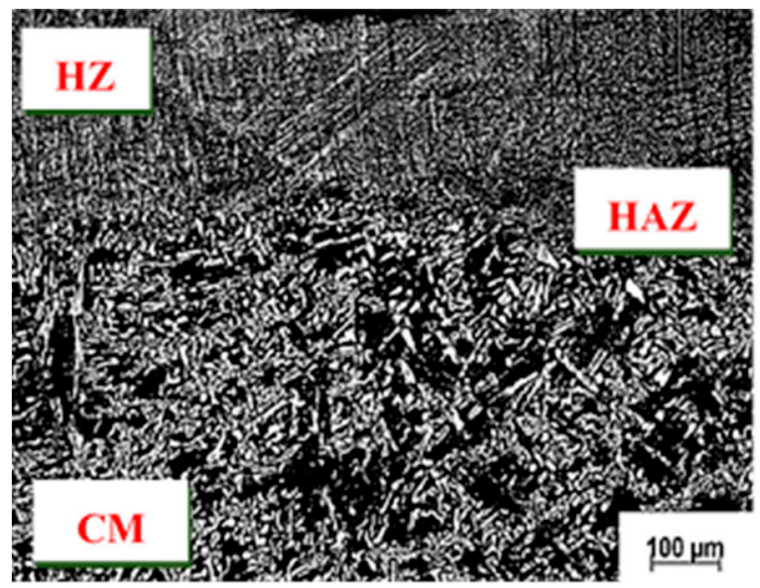

(a)

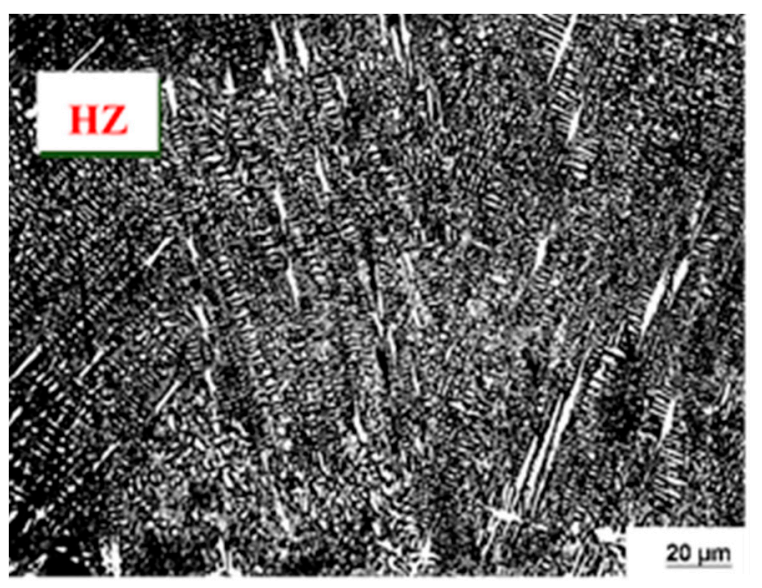

(b)

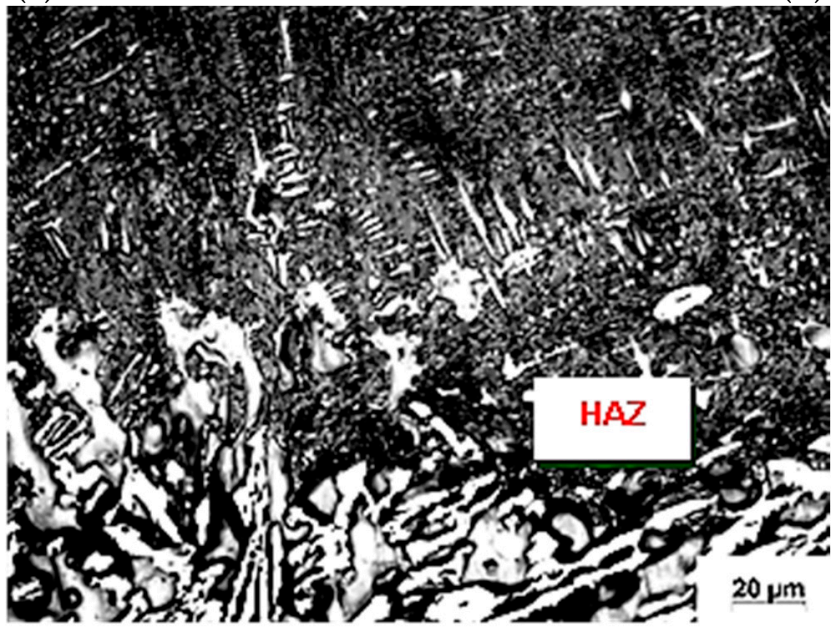

(c)

Figure 8. Typical microstructure features of laser heat-treated (LHT) S2 (Ni-hard 4) samples at a constant power of $1000 \mathrm{~W}$ and laser scanning speed of $5 \mathrm{~m} \cdot \mathrm{min}^{-1}$ : (a) the entire microstructure, (b) the hardened layer and (c) the heat affected zone at higher magnifications.

The hardening region clearly differs in microstructure from the non-transformed cast material. A remarkable structural observation is the change of globular shape to lamellar of the $(\mathrm{Cr}, \mathrm{Fe})_{7} \mathrm{C}_{3}$ eutectic carbides (Figure 8b), this is observed through the entire transformed zone. The HAZ consists of irregular $(\mathrm{Cr}, \mathrm{Fe})_{7} \mathrm{C}_{3}$ eutectic carbides and secondary carbides within the martensitic matrix as reveled in Figure 9. Such phases were confirmed via XRD analysis as shown in Figure 10.

According to Strum's work [31] the residual stress variation in the hardened layer can be described with the concentration of retained austenite, martensite and carbides in vol\%. In the hardened layer martensite transformation causes local increase of the microstructure volume and contributes to compressive residual stresses. Extra investigation of the residual stresses is planned for future work. 


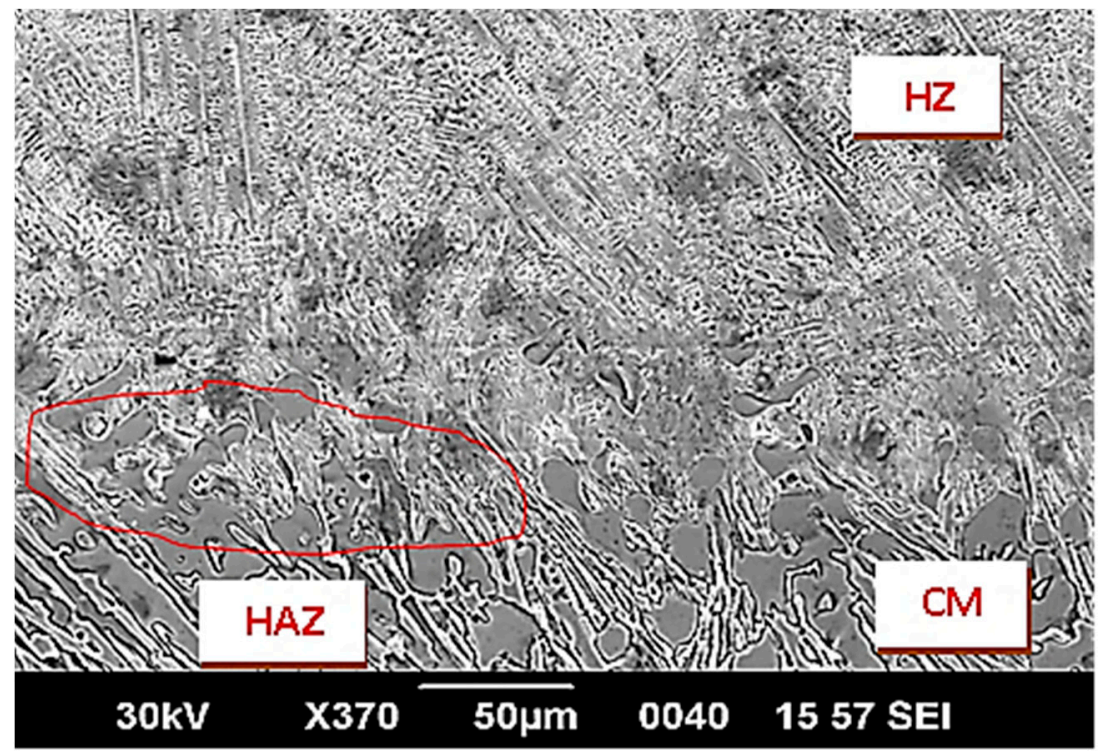

Figure 9. SEM microstructure: of the $\mathrm{HZ}$ and the HAZ of S2-1-3 sample.

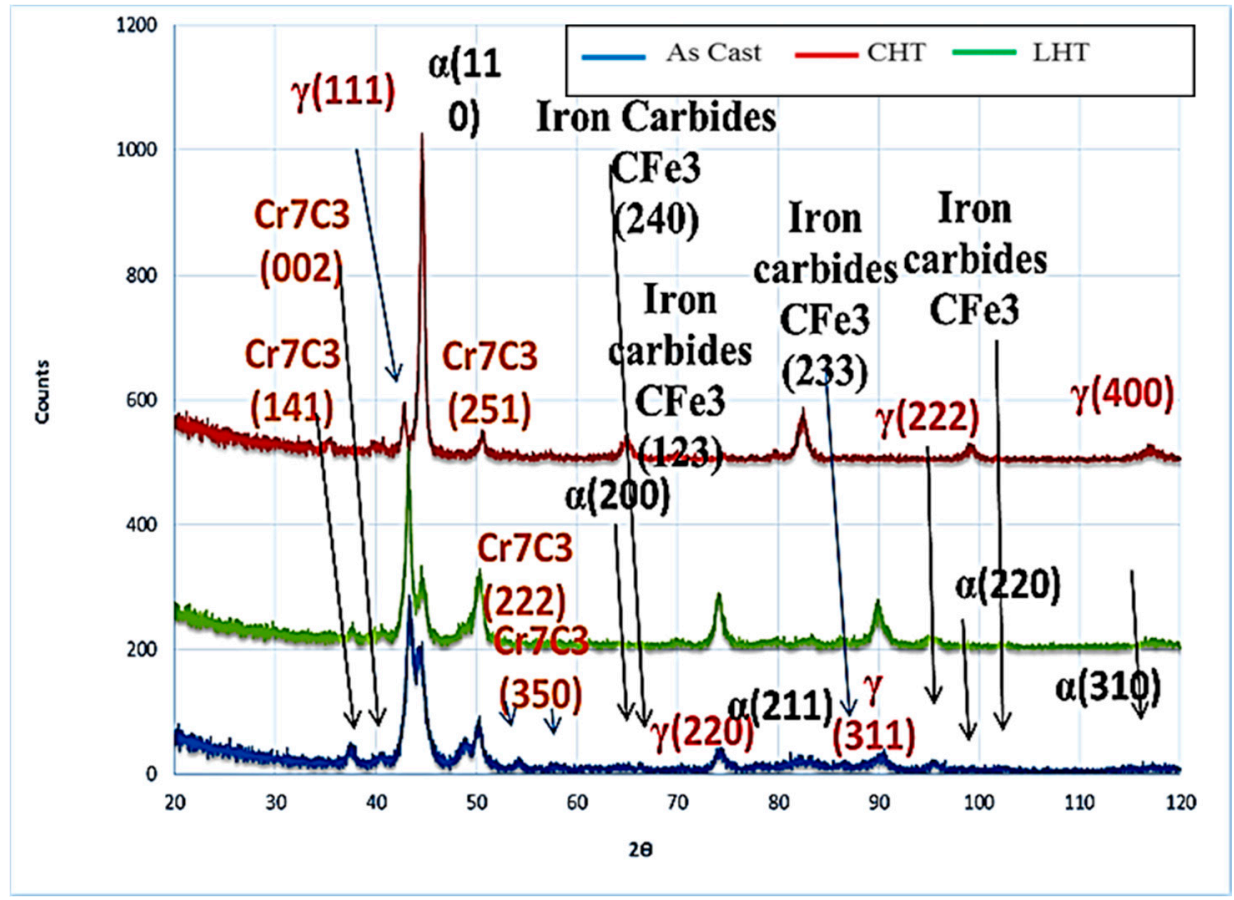

Figure 10. XRD Pattern of the S2(Ni-hard 4) as-cast, conventionally heat-treated and laser-treated samples.

\subsection{Hardened Depth}

The total hardened depth was evaluated by means of optical microscopy, from the outermost point of the hardened zone to the beginning of the interface zone. The measured depth recorded is an average of three measurements for each condition because of the wavy surface after laser hardening process. The data pointed out that the hardened depth is directly related to the heat input levels. The data presented in Figure 11 show that the hardened depth increases with the increase in the heat input. The shallowest hardened zone of S1 iron was $25 \mu \mathrm{m}$ and was associated with the least heat input level of $6 \mathrm{~J} \cdot \mathrm{mm}^{-2}$, while the deepest hardened thickness averages $500 \mu \mathrm{m}$ and corresponds to the highest heat input level of $\sim 17 \mathrm{~J} \cdot \mathrm{mm}^{-2}$. 


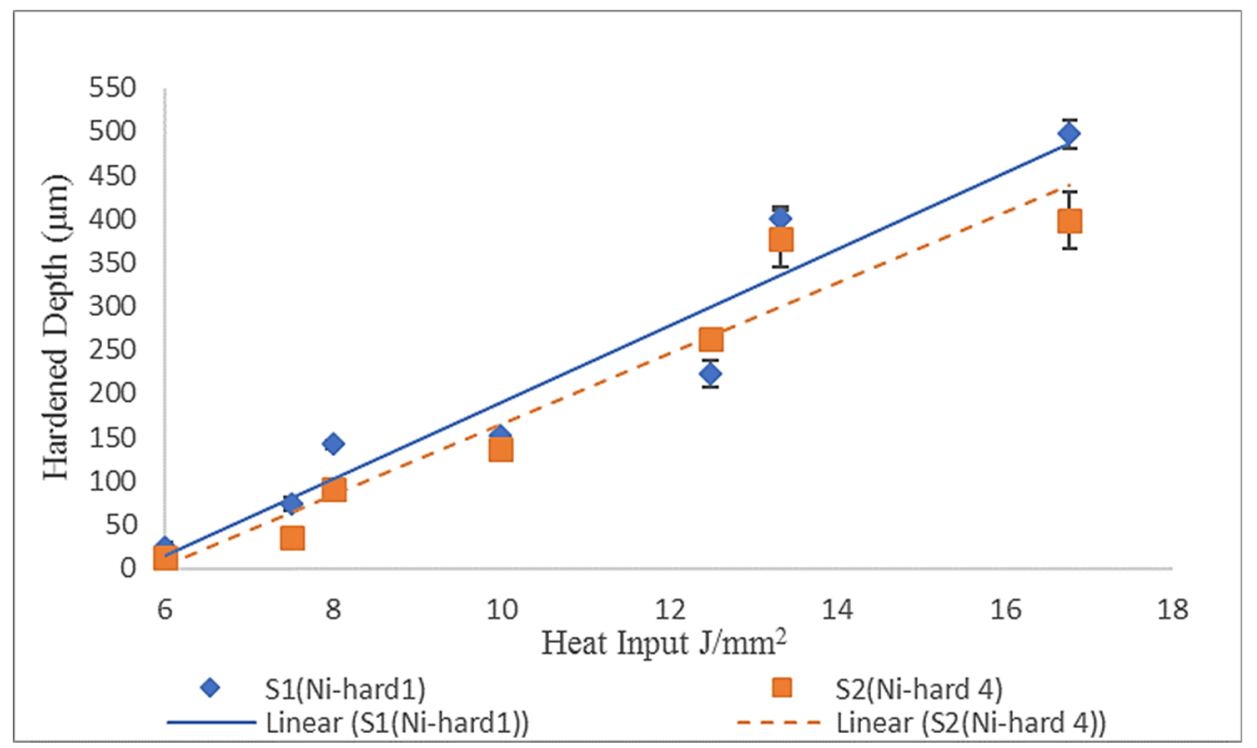

Figure 11. The hardened depth vs. the heat input values. Error bars represent standard deviation.

The corresponding samples of the S2 iron yield values for the hardened depth which range from $12 \mu \mathrm{m}$ to $400 \mu \mathrm{m}$. A thicker hardened layer was thus attained in S1 laser-treated samples compared to S2 samples. This may reflect that the different chemical compositions of the two alloys can result in different absorption levels of the laser energy during laser hardening. The variation of the hardened layer geometry is a direct consequence of the effect of incident laser energy fluctuations on the sample surface. With increasing the laser power, the incident laser energy on the substrate increases and thus a thicker layer of surface metal will be hardened [25].

\subsection{Hardness and Microhardness Distributions}

\subsubsection{S1(Ni-hard 1)}

The hardness is the physical property which directly reflects the power of laser surface hardening. The results of hardness measurements have confirmed the microstructure changes in the material. Figure 12 shows the average hardness values of the as cast, CHT and LHT samples. The average surface hardness value of the as cast S1 sample is $574 \mathrm{HV}$ and for CHT samples is $785 \mathrm{HV}$, whereas the hardness of the LHT is directly dependent on the values of the laser heat input. The surface hardness increased from 530 to $785 \mathrm{HV}$ corresponding to the lowest and the highest heat input values, respectively. Consequently, in order to achieve higher hardness than that of the untreated surface, a laser heat input higher than about $8 \mathrm{~J} / \mathrm{mm}^{2}$ is required. This hardness increment of the surface layer is caused most likely by the ultra-fine grained structure and high dislocation densities on the surface after the laser hardening [32].

In order to investigate the effect of laser treatment in the deeper layers in the surface, microhardness measurements were made. First, the microhardness of the as-cast Sl sample ranges from 590 to $627 \mathrm{HV}$ for $\mathrm{M}_{3} \mathrm{C}$ eutectic carbide and from 515 to $533 \mathrm{HV}$ for the matrix while, the CHT- samples yield microhardness values which range from 826 to $880 \mathrm{HV}$ for the eutectic carbide and from 710 to $765 \mathrm{HV}$ for the matrix. Figure 13 displays the microhardness distribution through the hardened zone towards the as-cast alloy for S1-1-3 sample. The hardened zone has the highest microhardness value of $1455 \mathrm{HV}$ which presumably due to the ultrafine martensite appearing in the matrix, with a lesser degree of austenite and a significant amount of dispersed $\mathrm{M}_{3} \mathrm{C}$ carbides [33]. A decline in the hardness levels from hardened zone towards the substrate was observed due to the microstructure difference and could be due to the annealing effect under the hardened zone that reducing the dislocation density 
induced by the laser hardening. Hence, laser surface hardening is a successful method for hardening cast irons with non-homogeneous microstructure.

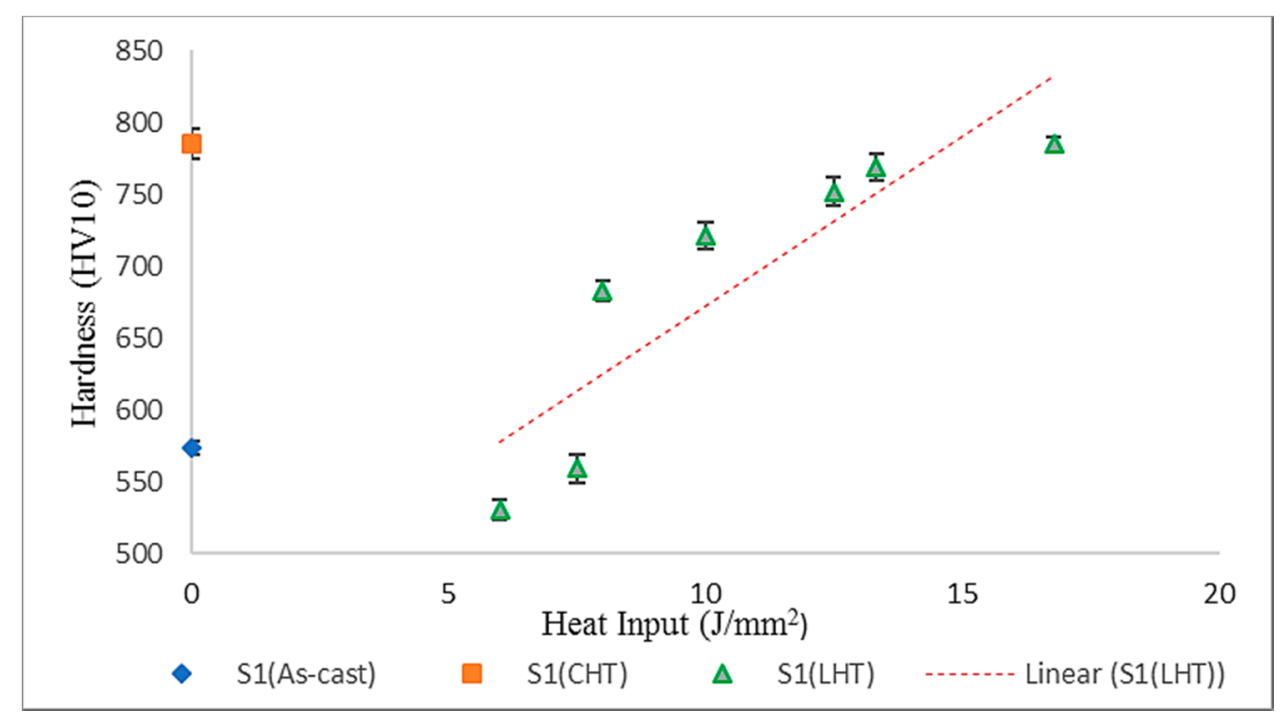

Figure 12. Hardness average values of LHT (S1 sample), CHT and As-cast samples. Error bars represent standard deviation.

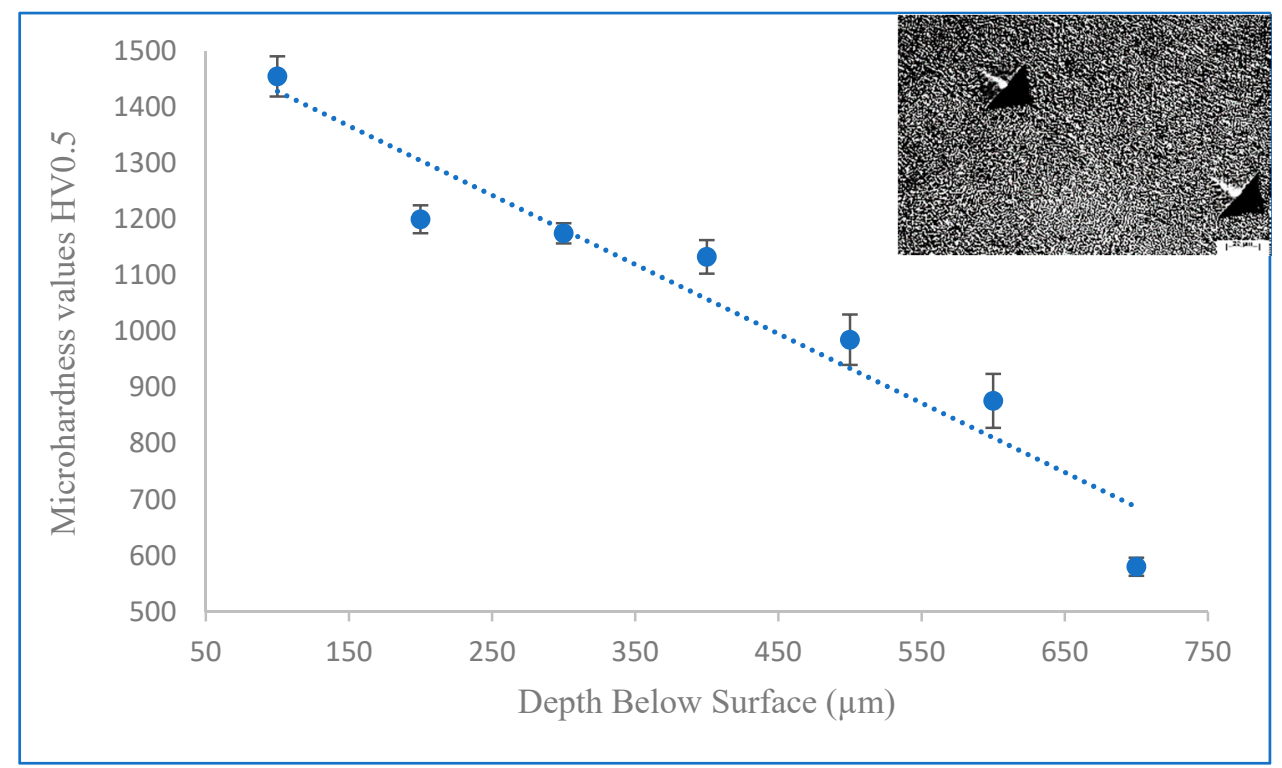

Figure 13. Microhardness distribution through S1-1-3 sample from the hardened layer towards as-cast zone. Error bars represent standard deviation.

\subsubsection{S2(Ni-hard 4)}

Similar hardness measurements were applied to S2 samples, see Figure 14. A higher surface hardness of S1 sample was recorded compared to the LHT S2 material. This is due to the higher carbon content ( $3.1 \mathrm{wt} \% \mathrm{C}$ ) of S2, this a consequence of more dissolution of carbon in austenite with the high heat input values which leads to a martensite formation with higher hardness values. 


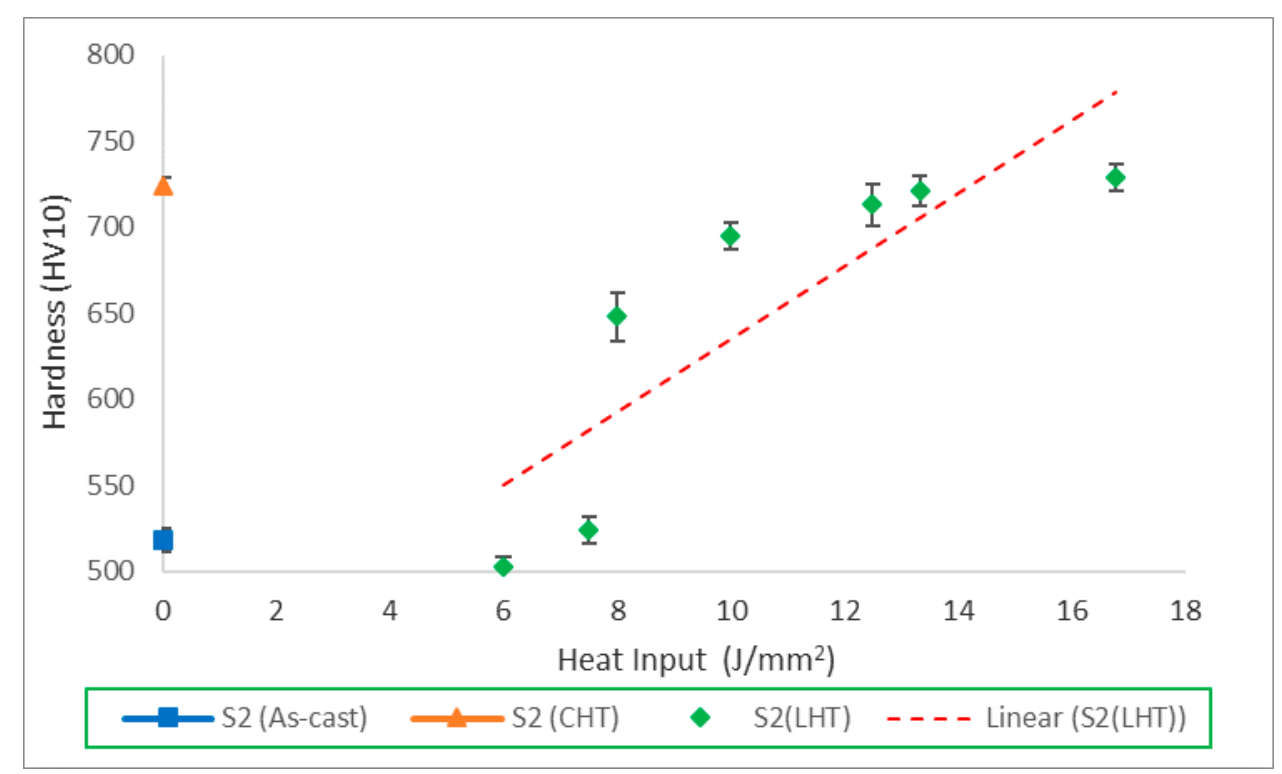

Figure 14. Hardness average values of LHT (S2 sample), CHT and As-cast. Error bars represent standard deviation.

A similar behavior concerning the microhardness distribution was observed as well in S2 samples, Figure 15. The highest hardness value of $\sim 1200 \mathrm{HV}$ was recorded in the hardened layer. Analysis of the microstructure and of the measured microhardness of the laser-hardened area leads to the conclusion that the laser hardening induced an increase in the microhardness of the Ni-hard 4 irons and this is due mainly to the appearance, in the matrix, of martensite and to a lesser degree of austenite with an insignificant amount of dispersed $(\mathrm{Cr}, \mathrm{Fe})_{7} \mathrm{C}_{3}$ carbides. It has been established that the hardened layer consists of large eutectic and many dispersed carbides of the $(\mathrm{Cr}, \mathrm{Fe})_{7} \mathrm{C}_{3}$ type located in an austenite-martensite matrix. This could be primarily attributed to the high concentration of the carbide-forming elements in the austenite and the fast heating and cooling, induced by such type of laser treatment [33]. It is noteworthy that the microhardness values of LHT S1 samples are higher than that recorded for LHT S2 samples. It could be attributed to the higher volume fraction of the $\mathrm{M}_{3} \mathrm{C}$ eutectic carbides in S1 samples that reaches $40-44 \%$ compared to the eutectic carbide $(\mathrm{Cr}, \mathrm{Fe})_{7} \mathrm{C}_{3}$ volume fraction of 20-28\% in the case of S2 samples as reported before [30]. Moreover, the martensite morphology and the amount of retained austenite that changes significantly throughout the hardened track, as shown in Figure 16.

The above-mentioned findings confirm the main advantage that justifies the application of the laser surface hardening is that the cooling rates are extremely fast due to the high temperature gradient applied locally on a small volume at the surface of a relatively massive and cold workpiece. Furthermore, the cooling rate is simply controlled by the scanning speed that moves the heat source away. As a result, the hardness achieved by this process is usually very high [34].

Finally, these cast irons are used extensively in applications requiring superior wear resistance and in practice, hardness is usually the best and only real means of quality control of Ni-hard alloys. These applications include crushing and grinding ores, mixing concrete, pulverizing coal and rolling metals which require harness values in the range of $500 \mathrm{HV}$ [29]. After laser hardening the hardness values increased by a factor of three higher than that recorded for the untreated alloys which means the increasing in the working lifetime of such component and the expectation of money saving which is an essential factor for successful engineering solutions. 


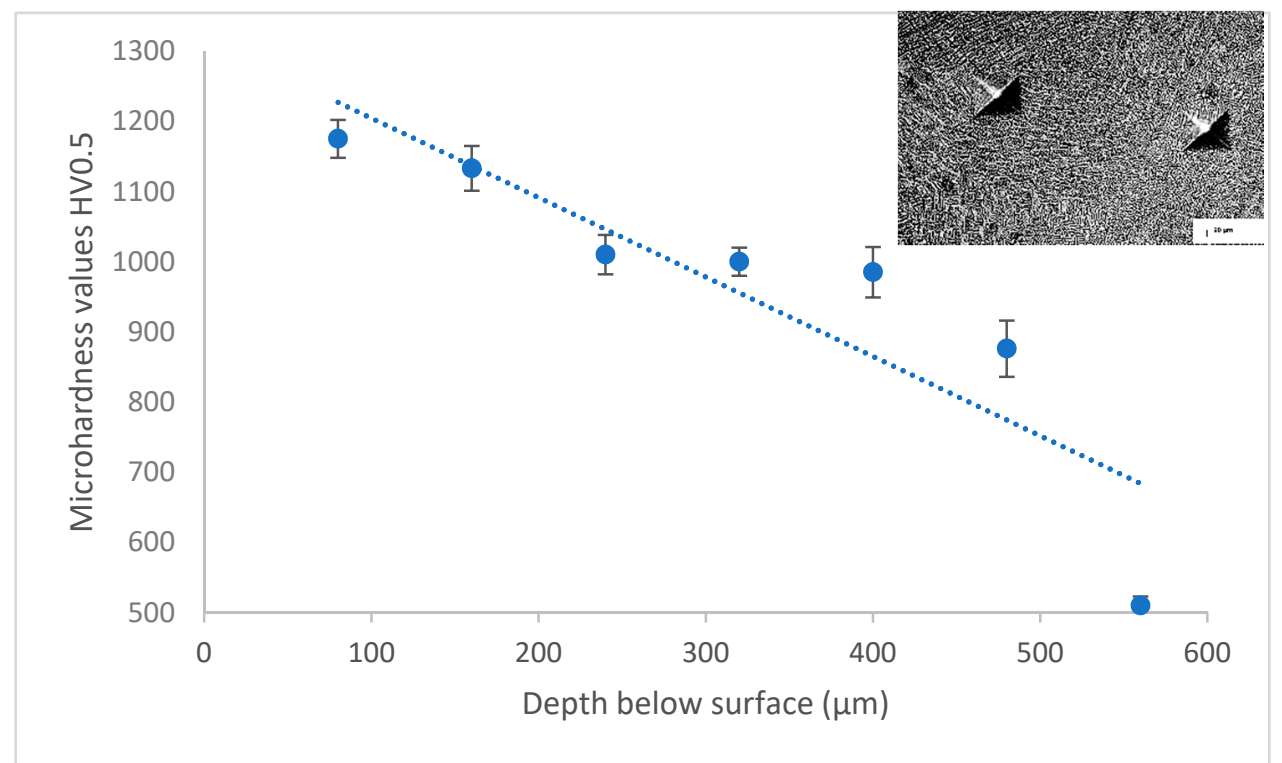

Figure 15. Microhardness distribution through S2-1-3 sample from the hardened layer towards as-cast zone. Error bars represent standard deviation.

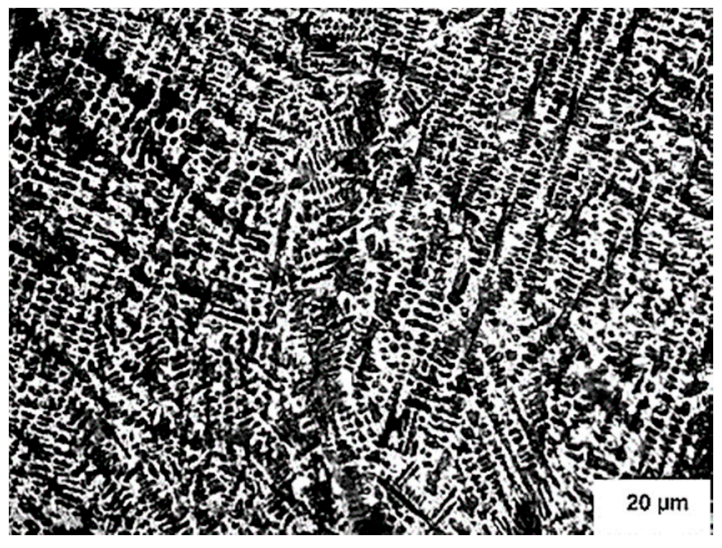

(a)

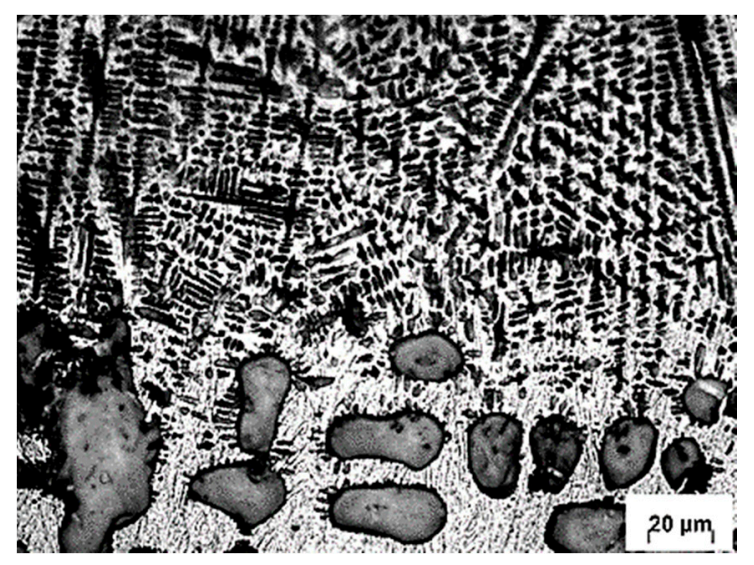

(c)

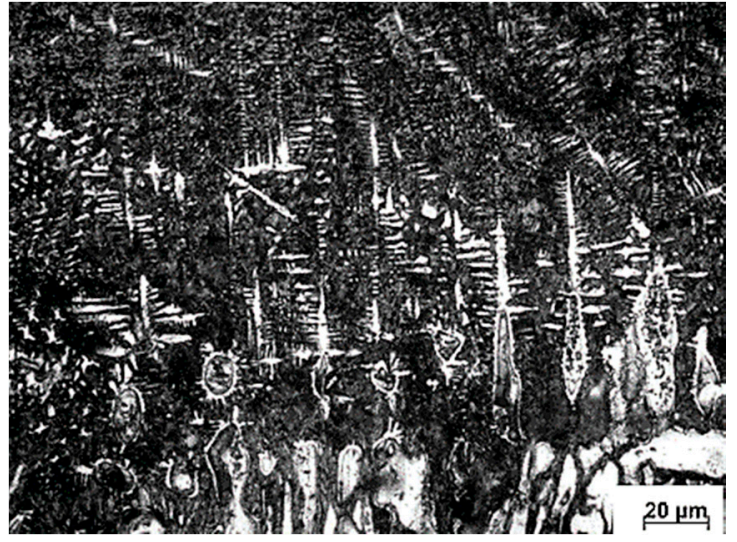

(b)

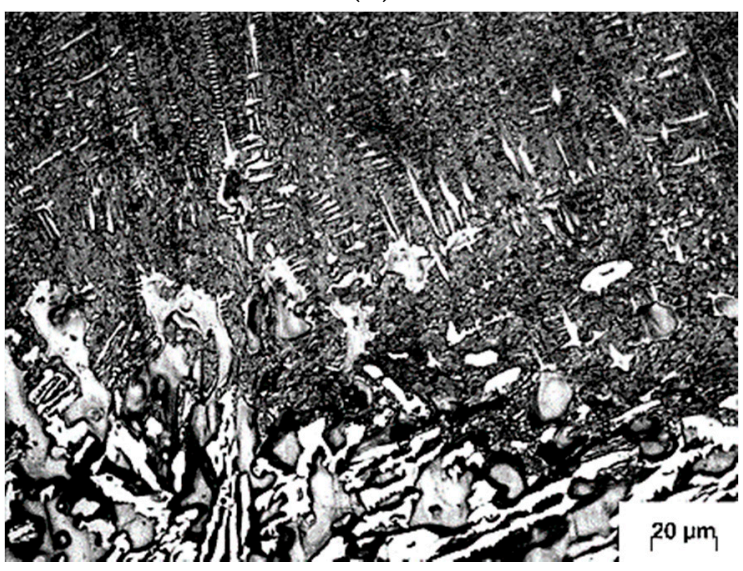

(d)

Figure 16. Microstructure of the different martensite morphologies of $S 1$ sample $(\mathbf{a}, \mathbf{c})$ and $S 2$ sample (b,d). 


\subsection{Wear Rate Behavior}

The variation of the hardness values was reflected on the wear behavior of the samples, the wear behavior is expressed as wear rate in $\mathrm{mg} \cdot \mathrm{min}^{-1}$. In untreated samples, severe wear rate greater than $8 \mathrm{mg} / \mathrm{min}$ and $9 \mathrm{mg} / \mathrm{min}$ for S1 and S2 alloys, respectively, was observed. Abrasive like SiC ( $2600 \mathrm{HV}$ 0.05) is much harder than both the matrix and carbide phases of Ni-hard specimens, so it is able to penetrate into the surface of the specimens and remove significant material during sliding, thus resulting in a low abrasion resistance (severe-wear rate). For this reason, laser hardening carried out to obtain different microstructures that play a significant role in enhancing the abrasion resistance. After laser surface-hardening, mostly mild and low wear rates have occurred for the samples, the wear rate was reduced by almost three times than the value of the untreated samples (for example, $2.8 \mathrm{mg} / \mathrm{min}$ versus $8 \mathrm{mg} / \mathrm{min}$, for $\mathrm{S} 1$ alloy) as shown in Figure 17 . This is due to the homogeneous martensitic transformation of the austenite dendrites in the microstructure that causes local increase of the microstructure volume and contributes to compressive residual stresses which resulted in the increase of the resistance to subsurface crack formation [31,35].

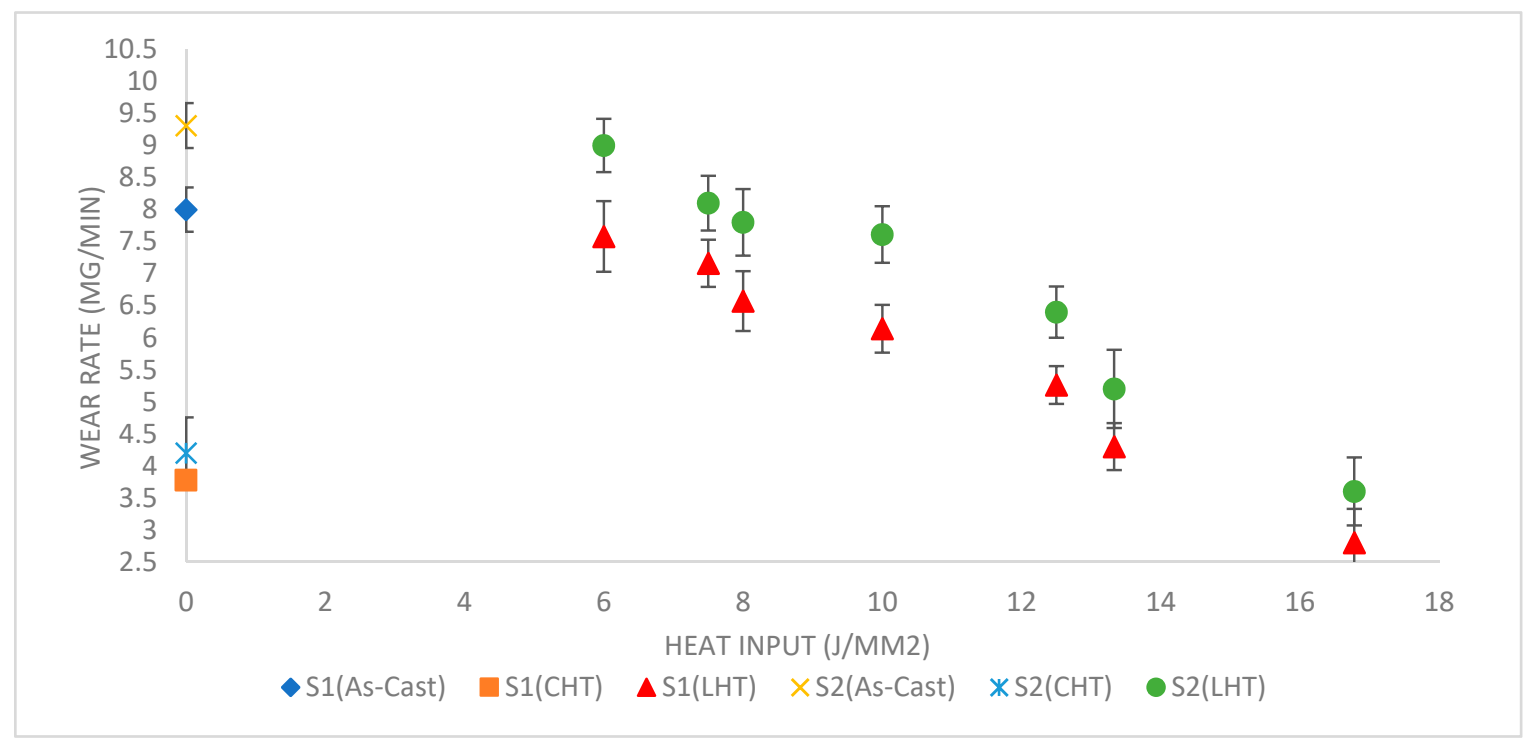

Figure 17. Wear rate behavior of as-cast, CHT and LHT S1 and S2 samples. Error bars represent standard deviation.

The wear diagram also shows that samples treated at high laser heat inputs exhibit the highest wear resistance, higher than that of conventionally treated samples $(2.8 \mathrm{mg} / \mathrm{min}$ for LHT-S1 versus $3.78 \mathrm{mg} / \mathrm{min}$ for CHT-S1). The faster cooling rate as achieved by laser hardening leads to martensite with higher hardness, ultrafine microstructure that extended to a depth of $500 \mu \mathrm{m}$ under the surface, and finally the structure stability of the martensite, bainite and secondary carbides. This was in accord with earlier report by Gadag [35].

On the other hand, the samples treated at low heat input suffer from severe wear weight loss, which is related to the thinner hardened layer (recall Figure 11). The wear rate measured in this case includes the wear of the hardened zone as well as the tougher heat affected zone which contains the as-cast matrix as was pointed earlier [25]. This explains the increase in the wear rate with the decrease in the heat input of the laser processing. Another important factor in the case of low laser heat input values, the solidification becomes very high due to the small molten volume and the high volume of surrounding cold bulk. This resulted in refining the eutectic carbides structure and significantly increased the wear rate.

Furthermore, the wear rate of LHT S1 sample is lower than that of S2 samples. This is a consequence of the higher hardness values in addition to the balance of the alloying element and the hard phases. 
Figure 18 demonstrates the optical microstructure of S1 sample after wear test. The microstructures indicate that at lower heat input values (below $10 \mathrm{~J} \cdot \mathrm{mm}^{-2}$ ), crack formation was observed. During LHT at low heat input values a small energy delivered to the substrate, which leads to high solidification rate (due to large thermal gradient) [20]. This resulted in crack formation, which is not acceptable in a production component. With increasing the laser heat input value, no evidence of any subsurface cracking during the wear test was detected. Subsequently, the laser hardening process should be optimized to avoid any crack formation.

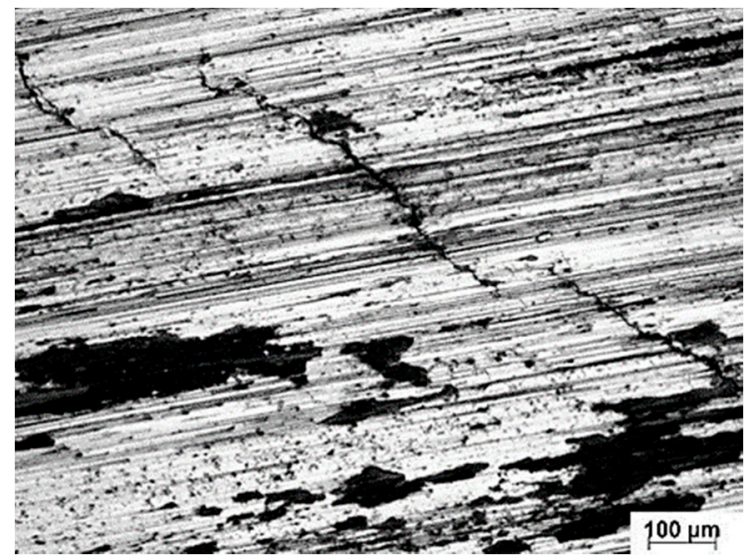

(a)

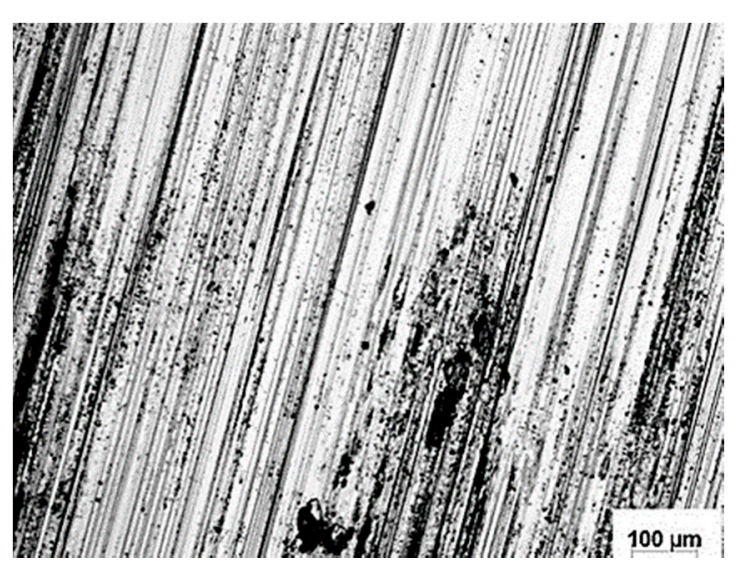

(b)

Figure 18. Optical microstructure after wear test of S1 LHT sample at (a) $6 \mathrm{~J} \cdot \mathrm{mm}^{-2}$ and (b) $16.78 \mathrm{~J} \cdot \mathrm{mm}^{-2}$.

\subsection{Impact Test Results}

Figure 19 exhibits impact energy values for As-cast, CHT and LHT of S1, S2 samples at different laser hardening conditions. After LHT S1 and S2 samples have both impact energy higher than that which was obtained from CHT samples despite the close values of the surface hardness levels that was achieved after both treatments. The corresponding incremental increase approaches $50 \%$ for both cases. Moreover, the attained impact energy from laser-treated samples is approximately equal to that of the as cast alloys although the surface hardness of the LHT is higher by nearly three times than the as-cast alloy. The present data also confirm that the impact energy is practically independent on the laser heat input values whereas, S2 impact level is higher than S1. It is noteworthy that the laser hardened zone represents a small fraction of the overall sample thickness and therefore the overall effect depends on both the hardened zone and the tougher interior cast alloy. The improved toughness of the laser-hardened material is presumably due to an increase of the amount of internal retained austenite in the microstructure. The refined microstructure as well as the high stresses induced during rapid cooling of the surface-treated surface are expected to retard the crack propagation during the fracture process and accordingly increase the toughness level. Even though the impact toughness data of the laser hardened samples show some similarity in their values, yet one cannot ignore their levels compared to the impact toughness of the CHT samples. In addition. it should be noted that the data reported here was rather limited, and mainly directed towards comparing the impact toughness levels between the conventional and the laser-treated samples. However, we conclude drawn that the results have some practical significance for impact toughness, as our objective was to find the heat input values that would lead to optimum mechanical properties (hardness, wear resistance and impact toughness). 


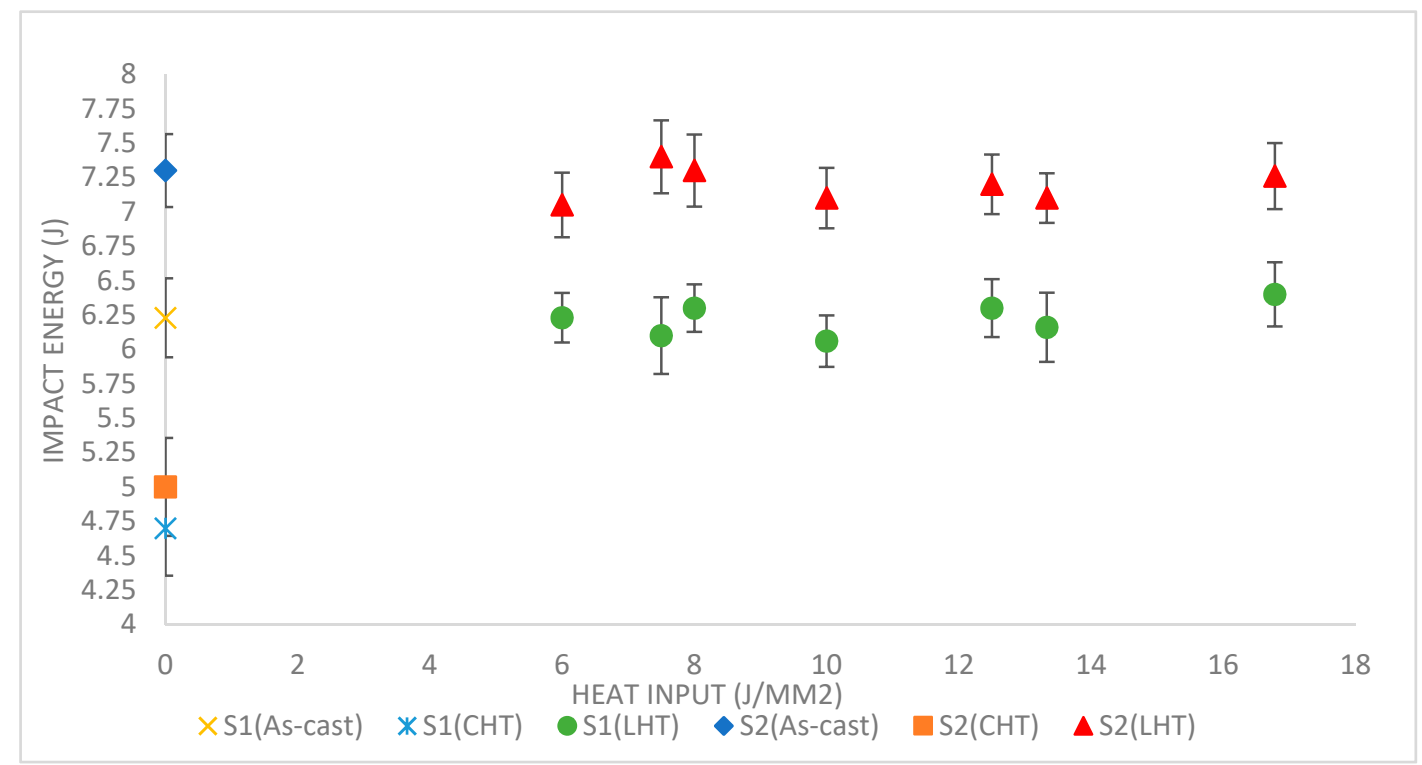

Figure 19. The impact energy profiles of As-cast, CHT and LHT of S1, S2 samples corresponding to laser heat inputs. Error bars represent standard deviation.

\section{Conclusions}

Laser hardening was successfully performed on Ni-hard 1 (S1) and Ni-hard 4 (S2) samples. A homogeneous microstructure is obtained in the laser hardened zone and both hardness and wear resistance were clearly improved. A proper processing window for laser hardening was established as a heat input ranges from 6 to $16.78 \mathrm{~J} / \mathrm{mm}^{2}$ in order to achieve the optimum condition that achieve acceptable mechanical properties.

(1) The hardened depth in both samples was observed to directly proportional to the laser heat input values. The shallowest hardened zone of S1 iron was 25 micrometers and was associated with the least heat input level of $6 \mathrm{~J} \cdot \mathrm{mm}^{-2}$, while the deepest hardened thickness averages $500 \mu \mathrm{m}$ and corresponds to the highest heat input level of $\sim 17 \mathrm{~J} \cdot \mathrm{mm}^{-2}$. The corresponding samples of the S2 iron yield values for the hardened depth which range from $12 \mu \mathrm{m}$ to $400 \mu \mathrm{m}$;

(2) The microhardness values clearly increased after laser hardening by almost three times for S1 sample ( $580 \mathrm{HV}$ to $1455 \mathrm{HV}$ ). Increment of hardness values of the surface layer is caused by the ultrafine-grained structure and high dislocation densities on the surface after the laser hardening.

(3) Analysis of the microstructure and of the measured microhardness of the laser-hardened area leads to the conclusion that the laser hardening induced an increase in the microhardness of the Ni-hard irons and this is due mainly to the appearance, in the matrix, of martensite and to a lesser degree of austenite with an insignificant amount of dispersed eutectic carbides;

(4) The wear resistance improved by nearly three times higher due to laser surface hardening. This is due to the martensitic transformation of the austenite dendrites in the microstructure that causes local increase of the microstructure volume and contributes to compressive residual stresses which resulted in the increase of the resistance to subsurface crack formation;

(5) The wear resistance depends on the hardened depth, the amount of laser heat input, hardness levels and compressive stresses obtained during the rapid cooling after laser processing;

(6) At lower heat input values (below $10 \mathrm{~J} \cdot \mathrm{mm}^{-2}$ ), crack formation was observed due to large thermal gradient resulted from the very rapid quenching during laser treatment. With increasing the laser heat input value, no evidence of any subsurface cracking during the wear test was detected. consequently, the laser hardening process should be optimized to avoid any crack formation;

(7) The attained impact energy from laser-treated samples is approximately equal to that of the as cast alloys although the surface hardness of the LHT is higher by nearly three times than the as-cast; 
(8) Laser surface treatment imparts resistance to subsurface crack initiation and propagation (at laser heat input above $10 \mathrm{~J} \cdot \mathrm{mm}^{-2}$ ), the refined microstructure as well as the high stresses induced during rapid cooling of the surface-treated surface are expected to retard the crack propagation during the fracture process and accordingly increase the toughness level. This makes laser surface hardening a good choice for improving impact toughness as was recorded by the present findings;

(9) The optimum condition for the laser hardening process corresponds to the highest laser heat input value $\left(16.78 \mathrm{~J} \cdot \mathrm{mm}^{-2}\right)$. It resulted in a high quality of hardened zone with crack free layer.

Author Contributions: Conceptualization, S.R.A.-S. and A.H.A.H.; methodology, S.R.A.-S., A.M.E.; validation, S.R.A.-S., A.M.E. and A.H.A.H.; formal analysis, S.R.A.-S. and A.M.E.; investigation, S.R.A.-S. resources, the samples were casted in the casting laboratory at the Central Metallurgical Research and Development Institute; data curation, S.R.A.-S. and A.M.E.; writing-original draft preparation, S.R.A.-S.; writing-review and editing, S.R.A.-S. and A.H.A.H.; visualization, S.R.A.-S. and A.M.E.; supervision, A.H.A.H. All authors have read and agreed to the published version of the manuscript.

Funding: This research received no external funding.

Conflicts of Interest: The authors declare no conflict of interest.

\section{References}

1. Al-Rubaie, K.S.; Pohl, M. Heat treatment and two-body abrasion of Ni-Hard 4. Wear 2014, 312, 21-28. [CrossRef]

2. Campbell, F.C. Elements of Metallurgy and Engineering Alloys; ASM International: Materials Park, OH, USA, 2008; ISBN 9780871708670.

3. Mohammadnezhad, M.; Javaheri, V.; Shamanian, M.; Naseri, M.; Bahrami, M. Effects of vanadium addition on microstructure, mechanical properties and wear resistance of Ni-Hard4 white cast iron. Mater. Des. 2013, 49, 888-893. [CrossRef]

4. Jinzhu, L.; Shizhuo, L.; Yongfa, M. Wear resistance of Ni-hard 4 and high-chromium cast iron re-evaluated. Wear 1993, 166, 37-40. [CrossRef]

5. Thorpe, W.R.; Chicco, B. The Fe-rich corner of the metastable C-Cr-Fe liquidus surface. Metall. Trans. A 1985, 16, 1541-1549. [CrossRef]

6. Laird, G.; Brown, R.R.; Nielsen, R.L. Factors affecting eutectic solidification of Cr-Ni (-Si-Mn) white cast irons. Mater. Sci. Technol. 1991, 7, 631-642. [CrossRef]

7. Karantzalis, E.; Lekatou, A.; Mavros, H. Microstructure and properties of high chromium cast irons: Effect of heat treatments and alloying additions. Int. J. Cast Met. Res. 2009, 22, 448-456. [CrossRef]

8. Laird, G.; Gundlach, R.; Rohrig, K. Abrasion-Resistant Cast Iron Handbook; American Foundry Society: Des Plaines, IL, USA, 2000; ISBN 9780874332247.

9. Tabrett, C.P.; Sare, I.R.; Ghomashchi, M.R. Microstructure-property relationships in high chromium white iron alloys. Int. Mater. Rev. 1996, 41, 59-82. [CrossRef]

10. Laird, G.; Nielsen, R.L.; Macmillan, N.H. On the nature of eutectic carbides in Cr-Ni white cast irons. Metall. Trans. A 1991, 22, 1709-1719. [CrossRef]

11. Pearce, J.T.H.; Chairuangsri, T.; Wiengmoon, A.; Poolthong, N.; Nomura, H. Use of electron microscopy on microstructure characterization of high chromium cast irons. Chin. Foundry 2006, 4, 38-43.

12. Smith, W.F. Structure and Properties of Engineering Alloys; McGraw-Hill Science/Engineering/Math: New York, NY, USA, 1993; ISBN 0070591725.

13. Pan, W.X.; Meng, X.; Li, G.; Fei, Q.X.; Wu, C.K. Feasibility of laminar plasma-jet hardening of cast iron surface. Surf. Coat. Technol. 2005, 197, 345-350. [CrossRef]

14. Liu, A.; Previtali, B. Laser surface treatment of grey cast iron by high power diode laser. Phys. Procedia 2010, 5, 439-448. [CrossRef]

15. Kennedy, E.; Byrne, G.; Collins, D.N. A review of the use of high power diode lasers in surface hardening. J. Mater. Process. Technol. 2004, 156, 1855-1860. [CrossRef]

16. Ion, J.C. Laser Processing of Engineering Materials: Principles, Procedure and Industrial Application; Butterworth-Heinemann: Oxford, MS, UK, 2005; ISBN 008097189X. 
17. Kusinski, J.; Kac, S.; Kopia, A.; Radziszewska, A.; Rozmus-Górnikowska, M.; Major, B.; Major, L.; Marczak, J.; Lisiecki, A. Laser modification of the materials surface layer-A review paper. Bull. Polish Acad. Sci. Tech. Sci. 2012, 60, 711-728. [CrossRef]

18. Hwang, J.; Lee, Y.; Kim, D.; Youn, J. Laser Surface Hardening of Gray Cast Iron Used for Piston Ring. JMEPEG 2002, 11, 294-300. [CrossRef]

19. Duffet, G.; Sallamand, P.; Vannes, A.B. Improvement in friction by cw Nd:YAG laser surface treatment on cast iron cylinder bore. Appl. Surf. Sci. 2003, 205, 289-296. [CrossRef]

20. Slatter, T.; Taylor, H.; Lewis, R.; King, P. The influence of laser hardening on wear in the valve and valve seat contact. Wear 2009, 267, 797-806. [CrossRef]

21. Adel, K.M.; Dhia, A.S.; Ghazali, M.J. The effect of laser surface hardening on the wear and friction characteristics of acicular bainitic ductile iron. Diyala J. Eng. Sci. 2008, 1, 110-121.

22. Májlinger, K.; Szabó, P.J. Laser treatment of cast iron engine cylinder bore with nanosecond laser pulses. Mater. Sci. Forum 2010, 659, 319-324. [CrossRef]

23. Marest, G.; Fontes, A.; Roigt, J.; Faussemagne, A.; Fayeulle, S.; Jeandin, M.; Benyagoub, A.; Moncoffre, N.; Frainais, M. Microstructure of nodular cast iron after excimer laser surface processing. Hyperfine Interact. 1995, 95, 227-245. [CrossRef]

24. Hechavarría, R.; López, G. Excimer laser surface treatment of a S.G. cast iron: Possible application for the running-in part of the automotive motors. J. Chem. Inf. Model. 2013, 53, 1689-1699. [CrossRef]

25. Al-Sayed, S.R.; Hussein, A.A.; Nofal, A.A.; Hassab Elnaby, S.I.; Elgazzar, H. Characterization of a Laser Surface-Treated Martensitic Stainless Steel. Materials 2017, 10, 595. [CrossRef] [PubMed]

26. Steen, W.M.; Mazumder, J. Laser Material Processing, 4th ed.; Springer: London, UK, 2010; ISBN 978-1-84996-061-8.

27. Jeffrey, A. ASM Handbook Volume 8: Mechanical Testing and Evaluation-ASM International; ASM International: Materials Park, OH, USA, 2004.

28. George, F.V. ASM Handbook: Metallography and Microstructures; ASM International: Materials Park, OH, USA, 2004; ISBN 9780871707062.

29. Doğan, Ö.N.; Hawk, J.A.; Rice, J. Comparison of three ni-hard i alloys. In Materials Science E Technology; SciTech Connect: New Orleans, LA, USA, 2004; DOE/ARC-2004-070.

30. Ni-Hard Material Data and Applications|Cast Iron|Steel. Available online: https://www.scribd.com/document/ 370995112/Ni-HardMaterialDataandApplications-11017-pdf (accessed on 1 November 2019).

31. Šturm, R.; Grum, J. The influence of retained austenite on residual stresses in laser remelted cast iron. J. Mater. Eng. Perform. 2011, 20, 1671-1677. [CrossRef]

32. Polytechnica, P.; Szabo, P. Effect of leaser treatment on the surface of cast iron cylinder bores. Period. Polytech. Mech. Eng. 2010, 54, 83-88. [CrossRef]

33. Gureev, D.M.; Yamshchikov, S.V. Change of Surface Properties of High-Chromium Cast Iron Under Conditions of Laser Treatment and Wear in a Pellet Stream. J. Sov. Laser Res. 1991, 12, 316-326. [CrossRef]

34. Chung, R.J.; Tang, X.; Li, D.Y.; Hinckley, B.; Dolman, K. Microstructure refinement of hypereutectic high Cr cast irons using hard carbide-forming elements for improved wear resistance. Wear 2013, 301, 695-706. [CrossRef]

35. Gadag, S.P.; Srinivasan, M.N. Dry sliding wear and friction: Laser-treated ductile iron. Wear 1994, 173, $21-29$. [CrossRef]

(C) 2020 by the authors. Licensee MDPI, Basel, Switzerland. This article is an open access article distributed under the terms and conditions of the Creative Commons Attribution (CC BY) license (http://creativecommons.org/licenses/by/4.0/). 